\title{
Comparison of measurements and models of bed stress, bedforms and suspended sediments under combined currents and waves
}

\author{
Rodolfo Bolaños ${ }^{1 *}$ \\ Peter D. Thorne ${ }^{2}$ \\ Judith Wolf ${ }^{3}$
}

${ }^{1}$ National Oceanography Centre, Joseph Proudman Building, 6 Brownlow Street, Liverpool, L3 5DA, UK.rbol@noc.ac.uk

${ }^{2}$ National Oceanography Centre, Joseph Proudman Building, 6 Brownlow Street, Liverpool, L3 5DA, UK. pdt@noc.ac.uk

${ }^{3}$ National Oceanography Centre, Joseph Proudman Building, 6 Brownlow Street, Liverpool, L3 5DA, UK.jaw@noc.ac.uk

* Corresponding author Phone: +44 (0) 151795 4958, Fax: +44 (0) 151795 4801, Email: rbol@noc.ac.uk (R. Bolaños) 
ABSTRACT

This study presents an analysis of data collected in an embayment off a sandy beach protected by shore-parallel breakwaters. Observations were carried out over a forty day period including spring and neap tidal cycles and low and high wave activity. Measurements were collected on the waves, currents, bedforms and suspended sediments and these were used to derive estimates of the bed shear-stresses, ripple dimensions, reference concentrations and suspended sediment profiles. The aim of the present study was to use the measurements to assess commonly employed empirical formulations applied to sediment modelling in the coastal marine environment. Assessments are made of four ripple predictors, two formulations of reference concentration and power law and exponential suspended sediment shape functions. In some cases predicted parameters are well represented during low wave conditions, while other parameters are better predicted under high wave events. The outcome from the work is an evaluation of the predictive capability of the selected empirical formulae at the sandy location and discussions on the comparison between the observations and predictions.

Keywords: Coastal processes, reference concentration, bed shear-stress, ripples, suspended sediment. 


\section{INTRODUCTION}

Nearshore and estuarine environments provide important habitats for coastal and marine life, while also supporting many human activities of industrial and leisure importance. The management of such areas requires knowledge of the physical and biogeochemical processes and therefore the observation, quantification and simulation of the coastal region is very important. Improving our capability to monitor and model the coastal marine environment is therefore essential in providing more sustainable development for these regions.

One of the most important processes in the coastal environment is the movement of sediment; this impacts on habitats, water quality, turbidity, biogeochemistry and morphology. The process of sediment transport depends on dynamic feedback interactions between the hydrodynamics, bedforms and sediment properties (Soulsby, 1997; Nielsen, 2009) and the term 'sediment triad' has been coined (Thorne and Hanes, 2002) to describe these interactions. The presence of bedforms modifies the bottom stress, nearbed turbulence and sediment entrainment. These in turn induce different bedform patterns, which collectively produce changes in bedload and suspended load and ultimately define the sediment transport pathways.

Sediment entrainment, transport and deposition are largely controlled by the bed shear-stress, which is related to the hydrodynamic and bed conditions. Sediment transport rates are often considered to be directly related to values of bed shear-stress in steady uniform flows. To calculate the bed shear-stress in current-dominated conditions is a relatively simple process. Methods of calculation include the inertial dissipation approach, law of the wall, Reynolds stresses and various empirical formulae (Biron et al., 2004; Green, 1992; Kim et al., 2000; Soulsby, 1997) in which the stress depends on the roughness of the bed and the mean current 
velocity. For a wave-dominated environment it can be difficult to obtain estimates of the shear-stress directly through flow measurements within the wave boundary layer and it is therefore usually related to the bottom orbital wave velocity and an estimate of bed roughness (Soulsby, 1997; Nielsen, 1992). For combined wave and current conditions the formulation to use is somewhat more uncertain due to the possibility of nonlinear interactions as the flow becomes more energetic (Soulsby et al., 1993; Soulsby, 1997). For the study here we have adopted the approach of Soulsby and Clarke (2005) who have proposed an expression for combined current-wave stresses for rough and smooth beds involving a simple explicit method. The reason for adopting this method is that it has been validated against a wide range of data.

In order to calculate the suspended sediment transport at a location, vertical profiles of sediment concentration and flow need to be known. The suspended concentration profile is often expressed as the product of a reference concentration specified close to the bed, which provides the absolute level of the suspended load, and a shape function which represents the variation in the concentration profile with height above the bed. The reference concentration is sometimes related to the excess shear-stress, given by the difference between the threshold of bed shear-stress for sediment motion, and the skin friction bed shear-stress (Van Rijn, 1984), another common approach developed by Nielsen (1986) uses a modified Shields parameter and more recently Lee et al. (2004) have related the reference concentration to the inverse Rouse parameter and the Shields parameter. Here the latter two approaches are compared with the observations. This was because these formulations were mainly based on data collected in sandy environments similar to that of the present study. The shape function is commonly represented by one of three semi-empirical formulations based on uniform, linear and parabolic variations of the sediment diffusivity with height above the bed. These 
respectively give shape functions which are exponential, power law and Rouse (Soulsby, 1997), with the latter being approximated by the power law in the bottom $25 \%$ of the water column. The exponential profile is typically specified by a vertical mixing length which is dependent on grain size, wave conditions and bedforms and the Rouse and power law profiles are dependent on the Rouse parameter which depends on grain size and total bed friction velocity. The suspended sediment measurements collected in the present study were within the first metre above the bed in a mean water depth of $4.5 \mathrm{~m}$ and therefore the exponential and power law shape functions are compared here with the observations.

Sediment movement in response to hydrodynamic forcing ubiquitously tends to generate bedforms. These bedforms can cover a broad range of scales and can modify the sediment entrainment, the bottom stress and boundary layer processes. Bedforms are an indication of bedload sediment transport and can be used to estimate its direction and magnitude, which is proportional to the product of the ripple migration rate and the ripple height (e.g. Holmedal and Myrhaug, 2004). Bedforms also impact on the mechanism of sediment entrainment, from diffusive to convective vortex processes and depending on the type of mechanism different shape functions and reference concentrations arise (Ribberink and Al-Salem, 1994; van der Werf et al., 2006; Thorne et al., 2009). Owing to the impact bedforms are deemed to have on the hydrodynamics and sediment processes, there have been many studies to measure and predict ripple formation, type and dimensions (Nielsen, 1992; Williams et al., 2005; Davis et al., 2004; Soulsby and Whitehouse, 2005; Traykovski, 2007; Grant and Madsen, 1982; Pedochi and Garcia, 2009). However, there is still a high degree of scatter in the presented data sets, particularly when associated with field observations, and predictions are variable, depending on the formulation chosen. For the present work we have chosen to assess the ripple predictions of Grant and Madsen (1982), Nielsen (1992) and the more recent works of 
Soulsby and Whitehouse (2005) and Pedocchi and Garcia (2009), the latter two of which are based on comprehensive data sets from the laboratory and the field.

For regional area modelling of sediment transport, the dynamic feedback processes mentioned in the previous paragraphs are usually represented by empirical parameterisations to characterise the complex hydrodynamics-bedform-sediment interactions (Amoudry and Souza, 2011). The present work focuses on an assessment of such parameterisations by means of model-data comparisons in a sandy embayment within shore-parallel breakwaters. The aims of this work are, firstly, to present a comprehensive set of field measurements, including the hydrodynamics, suspended sediments and bedforms and, secondly, to evaluate commonly used formulations for predicting ripple dimensions, reference concentration and sediment concentration profiles.

In section 2 the field site, instrumentation and data collected are outlined. In section 3 the data analysis, empirical formulations and comparison between the predictions and the observations are presented and assessed. Finally in section 4 the conclusions are presented. 


\section{FIELD SITE AND DATA COLLECTED}

\subsection{Local environment}

As part the LEACOAST2 project (Wolf et al., 2008; Pan et al., 2011), data were collected at Sea Palling on the north Norfolk coast, UK, during two field campaigns to study sediment transport processes. The first of the two campaigns was carried out between March-May 2006 and an instrumented bed platform frame, designated as F3, collected one of the more comprehensive data sets from both studies. It is this data set which is presented, analysed and compared here with predictions. The location of the study site, the position of F3 and the frame itself, are shown in Fig. 1. It can be seen in the figure that the area was characterized by the presence of nine shore parallel breakwaters that had developed tombolos at the four more northerly breakwaters. The local mean tidal range was about $3 \mathrm{~m}$, on a mean water depth of $4.5 \mathrm{~m}$, with tidal currents reaching $0.7 \mathrm{~ms}^{-1}$ offshore of the breakwaters and flowing in the northwest-southeast direction. The tidal velocities behaved as those of a progressive wave, with maximum velocities near high and low water. However, shoreward of the breakwaters where F3 was located, due to the presence of the tombolos, tidal flow was more complex and peaked at around $0.2 \mathrm{~ms}^{-1}$ under low wave conditions. At high water the currents were similar to offshore, flowing in the northwest-southeast direction, however, at low water the tidal flow was restricted to entering between the breakwaters and thus currents flowed in the northeast-southwest direction. Within the embayment where F3 was located, the waves had a significant wave height, $H_{s}$, of $0.3 \mathrm{~m}$ during low wave conditions and this increased to a maximum of $H_{s} \approx 1.5 \mathrm{~m}$ during high wave event conditions. Peak wave periods, $T_{p}$, were in the range of $2-12$ seconds. The direction of the waves entering the embayment was primarily from the northeast. 
The sediments at the Sea Palling site were mainly sandy, although gravel and medium silt was also present. The size distribution of the sediments was therefore somewhat heterogeneous and broad, as has been reported in Noyes (2007). Grab samples close to F3 showed a size distribution that had a nominally log-normal size distribution, with the particle size ranging between $20 \mu \mathrm{m}-800 \mu \mathrm{m}$ with $d_{10}=151 \mu \mathrm{m}, d_{50}=255 \mu \mathrm{m}$ and $d_{90}=405 \mu \mathrm{m}$. The sediments local to F3 therefore had moderate sorting.

\subsection{Instrumentation and measurements}

F3 collected one of the more complete data sets covering hydrodynamics, bedforms, suspended sediments and nearby samples of the bottom sediment. As shown in Fig. 1, F3 was deployed inshore of the breakwaters and was instrumented with an acoustic Doppler velocimeter (ADV), a three frequency acoustic backscatter system (ABS), an acoustic ripple profiler (ARP), and a Laser In-Situ Scattering and Transmissometry (LISST). The ADV was mounted at $0.5 \mathrm{~m}$ above the base of the frame and was set to record the three orthogonal components of velocity and pressure at a sampling frequency of $16 \mathrm{~Hz}$ with records collected hourly for 20-minute burst periods. These data were the source of the hydrodynamic and water surface elevation information. The use of the ABS to measure suspended sediment concentration dates back to the 1980s (Young et al., 1982; Thorne and Campbell, 1992; Crawford and Hay, 1993; Thorne and Hardcastle, 1997; Hurther et al., 2011). The ABS collected profiles of the backscattered signal from the suspended sediments synchronous with the ADV. The ABS used transducers operating at frequencies of 1.0, 2.0 and 4.0 MHz, with a pulse repetition rate of $128 \mathrm{~Hz}$, over a range of $1.28 \mathrm{~m}$, with a vertical sampling resolution of $0.01 \mathrm{~m}$. The data were inverted to provide burst-averaged profiles of suspended sediment concentration. A significant advantage of the acoustic approach over other techniques (such 
as optical) is that the bed echo can be detected and the bed location identified. The measured concentration profiles can therefore be directly related to the local time-varying bed position. Knowledge of the time-varying bed location is critical to obtaining accurate estimates of the reference concentration. The ARP operated at a frequency of $1.1 \mathrm{MHz}$ and provided the bed height over a transect of $2 \mathrm{~m}$ with an along track resolution of $0.01 \mathrm{~m}$ and a vertical accuracy of $0.002 \mathrm{~m}$ (Thorne and Hanes, 2002; Williams et al., 2005; Hurther and Thorne, 2011). A transect of the bedforms was collected every half hour. The LISST was mounted $0.99 \mathrm{~m}$ above the base of the frame and was used to provide an hourly estimate of $d_{50}$ for the background suspended sediment load.

Fig. 2 presents an overview of the main data sets analysed in this study. The data covered a period of 41.7 days (1000 hours) and encompassed many different hydrodynamic, suspended sediment and bedform conditions. Fig. 2a shows the water elevations from the pressure transducer located on the ADV and this clearly illustrates the tidal variation and the springneap cycles. The northerly and easterly velocity components measured by the ADV are given in Fig. $2 b$, where it can be seen that the tidal velocities peak at around $0.2 \mathrm{~ms}^{-1}$, with some enhancement during periods of high wave activity due to the combined effect of storm surge and wave induced currents. It can also be observed in Fig. $2 b$ that the easterly flood flow was the dominant current. The wave parameters are shown in Fig. $2 \mathrm{c}$ and 2 d. The significant wave height was typically less than $0.3 \mathrm{~m}$ during low wave conditions, with a series of wave events around hours $120-220,270-330,580-620,740-830$ and 900-1000, where the value for $H_{s}$ was notably higher, with a maximum value close to $1.5 \mathrm{~m}$ at hour 180 . The values for $T_{p}$ were quite variable, with the oscillations in $T_{p}$ under low energy wave conditions being associated with weak swell combined with some local wave generation and having a tidal modulation due to the changes in water depth, with the shortest peak periods occurring during low tide. 
During high wave events the value for $T_{p}$ was less variable due to more uniform forcing from the north-east, with resulting values for $T_{p}$ in the region 7-12 s. The ABS suspended sediment concentration is given in Fig. 2e, where it can be observed that significant suspension events were associated with the periods of higher wave activity. During low wave conditions, sediments were entrained into the water column due to wave stirring at low water, at a magnitude an order or two below those observed during high wave conditions. At 200 hours into the record, there is seen to be an apparent increase in bed level, however this is actually associated with a settling of frame F3 into the bed sediments during the onset of the passage of the first high wave event. The ripple measurements from the ARP (Fig. 2f) show relatively consistent features in the periods of low wave activity, with a change in form during the passage of the high wave events. There was therefore a nominally consistent pattern over the deployment period, of relatively low levels of suspended load and moderate bed ripple activity during periods of low waves, while during high wave events the nearbed suspended concentration levels were increased by up to two orders of magnitude and bedform activity was more dynamic. 


\section{DATA ANALYSIS AND RESULTS}

\subsection{Hydrodynamics}

Current and wave data were obtained from the ADV velocity and pressure sensor. Detailed quality control checks, including despiking of the ADV data, were carried out. The approach taken was that of Goring and Nikora (2002), modified by Wahl (2003), whereby the despiking method removes erroneous data values in the time series while conserving the main original temporal structure. The ADV data used here had very few spikes and the data are considered to be highly reliable.

For the estimation of wave parameters the PUV method (Krogstad, 1991; Wolf, 1997) was applied to the despiked ADV velocity and pressure data. This method uses linear wave theory to compute the depth attenuation of velocity and pressure spectra and convert the data observed to the mean surface wave elevation spectra using:

$$
\begin{aligned}
& S_{p}(f)=\left[\frac{\cosh (k h)}{\cosh \left(k\left(z_{h}\right)\right)}\right]^{2} \frac{C_{p}(f)}{\rho^{2} g^{2}} \\
& S_{u}(f)=\left[\frac{\sinh (k h)}{\cosh \left(k\left(z_{h}\right)\right)}\right]^{2} \frac{C_{u}(f)}{\omega^{2}}
\end{aligned}
$$

where $S_{p}$ and $S_{u}$ are surface elevation spectra derived from the power spectrum densities of bottom pressure and bottom horizontal velocity, $C_{p}, C_{u}$, respectively, where $k$ is the wave number at angular frequency $\omega, h$ is the burst mean water depth, $z_{h}$ is the distance of the instrument above the bed, $g$ is gravity and $\rho$ is water density. In the present study, the difference in surface elevations derived from the pressure spectra and velocity spectra had a maximum normalised standard deviation of $20 \%$, therefore the results were quite comparable, 
however, the velocity spectrum was more affected by noise and the pressure spectra were therefore used to obtain surface elevation.

Taking into account the ambient current, the surface wave dispersion relation can be expressed as:

$$
\omega_{i}=\sqrt{g k_{i} \tanh k_{i} h}+k_{i} U \cos \alpha_{i}
$$

for each discrete $\omega_{i}$ in the spectrum, with wave number $k_{i} . U$ is the current speed and $\alpha_{i}$ is the angle between the $i^{\text {th }}$ frequency wave component and the current. The mean wave direction was estimated by comparing the magnitude of the cross spectra at each spectral frequency, $f_{i}$ :

$D\left(f_{i}\right)=\tan ^{-1}\left(C_{p e}\left(f_{i}\right) / C_{p n}\left(f_{i}\right)\right)$

where $C_{p e}$ is the co-spectrum of pressure and east current and $C_{p n}$ is the co-spectrum of pressure and north current.

Spectral forms of the standard wave parameters are defined with reference to the spectral moments:

$$
m_{n}=\int_{0}^{\infty} f^{n} S_{p}(f) d f
$$

Thus the significant wave height was calculated using:

$$
H_{s}=4 \sqrt{m_{0}}
$$

The values for $H_{s}$ and the peak wave period of $S_{p}(f), T_{p}$, were presented in Fig. 2. The ratio of $H_{s}$ to the water depth was less than 0.3 for the whole period, which is lower than the value of 
0.7 required for breaking waves; therefore wave breaking was not a significant process in this study.

As previously mentioned, shear-stress is an important parameter in sediment studies and in a wave dominated environment where the wave boundary layer is typically less than $0.1 \mathrm{~m}$ in thickness, it is difficult, particularly in the field, to obtain flow measurements within this boundary. In the present study, flow in the wave boundary layer was not measured directly and an empirical formulation was therefore used to estimate the bottom stress due to combined waves and currents. The method of Soulsby and Clarke (2005), developed from an earlier formulation (Soulsby, 1997), calculates the total bottom stress for a flat bed, from integral wave parameters and mean flow properties; this stress is responsible for the sediment entrainment. The bed grain size must be supplied, which is used to define a roughness length, $z_{o}=d_{50} / 12$ (Nielsen, 1992; Soulsby, 1997). An important simplifying assumption is that the wave component of the stress is not enhanced by the presence of the current. This is valid for wave-dominated conditions and allows for the specification of an eddy viscosity inside the wave boundary layer in terms of wave and current stress only which makes the solution explicit. The tidal current is treated as a steady flow. This method calculates the mean, maximum and root-mean-square bed shear-stresses in combined waves and currents, for a range of conditions from hydrodynamically smooth to rough turbulent, without requiring an iterative procedure. Soulsby and Clarke (2005) report that this new method gives better agreement with published data than existing methods and is quick to compute since it uses an explicit algorithm. The expression used to calculate the maximum shear-stress is given below:

$$
\tau_{\max }=\left[\left(\tau_{m}+\tau_{p}|\cos \alpha|\right)^{2}+\left(\tau_{p}|\sin \alpha|\right)^{2}\right]^{1 / 2}
$$


where $\tau_{m}$ is the mean bed shear-stress during a wave cycle under combined waves and currents, $\tau_{p}$ is the amplitude of the oscillatory bed shear-stress under combined waves and currents and $\alpha$ is the angle between waves and current direction. Further details on the derivation of the terms in equation (6) can be found in Soulsby and Clarke (2005). In the present field study the waves were irregular and therefore for the evaluation of their expressions we have used integrated parameters, $H_{s}$ and $T_{p}$, to represent the wave conditions.

For some of the expressions used in the present study, the formulations are based on waves only and the commonly used wave shear-stress was calculated as:

$$
\tau_{w}=\frac{1}{2} \rho f_{w} U_{w}^{2}
$$

The wave friction factor, $f_{w}$, is defined as (Soulsby, 1997):

$f_{w}=1.39\left(\frac{A_{w}}{z_{0}}\right)^{-0.52}$

$U_{w}$ is the wave orbital velocity amplitude at the seabed given by $\pi H_{s} /\left(T_{p} \sinh \left(k_{p} h\right)\right)$ and $A_{w}$ is the wave orbital amplitude at the bed given by $H_{s} /\left(2 \sinh \left(k_{p} h\right)\right) . k_{p}$ is the peak wave number obtained from equation (2) with angular frequency $\omega_{P}=2 \pi / T_{p}$. Shown in Fig. 3 are the calculated values for the skin friction shear-stress for currents alone based on a logarithmic velocity profile, $\tau_{c}$ (red line), waves alone, $\tau_{w}(+)$ and maximum wave-current, $\tau_{\max }$ (black line). Also shown in Fig. 3 is the critical shear-stress of motion, $\tau_{c r}$, for $d_{50}$ of the bed, having a value of $\tau_{c r}=0.2 \mathrm{Nm}^{-2}$, calculated from the Shields parameter, $\theta=\frac{\tau}{g\left(\rho_{s}-\rho\right) d_{50}}$, using Soulsby (1997) expression for the critical Shields value:

$$
\theta_{c r}=\frac{0.3}{1+1.2 D}+0.055\{1-\exp (-0.02 D)\}
$$


where $D=d_{50}\left(\frac{g(s-1)}{v^{2}}\right)^{1 / 3}, g=9.81 \mathrm{~ms}^{-2}, s$ is the ratio of densities of sediment grains $\rho_{s}=2650$ $\mathrm{kgm}^{-3}$ and water $\rho=1023 \mathrm{kgm}^{-3}$ and $v=1.36 \cdot 10^{-6} \mathrm{~m}^{2} \mathrm{~s}^{-1}$. As can readily be seen, the current alone would not have moved the median bed sediments. It is the waves that generate sufficient shear-stress to significantly mobilise the bed sediments, particularly the high wave events. As shown in Fig. 3 the tidal currents did not generate large bed shear-stresses, therefore the wave-current interactions were relatively weak at the location of the present study.

It is the skin friction component of the total shear-stress which is considered to be relevant to the initiation of sediment movement on the bed and consequently pertinent to the development of bedforms (Soulsby, 1997; Grant and Madsen, 1982) and the magnitude of the reference concentration (Lee et al., 2004). Therefore in the following calculations for bedforms and reference concentrations it is the skin friction component of the shear-stress from equations (6) and (7) which is used to obtain the friction velocity and Shields parameter. The skin friction calculations were based on a bed roughness length, $z_{o}$, given by $d_{50} / 12$. However, for the turbulent entrainment of sediment further up into the water column it is the form drag which is important for the diffusion of suspended particles upwards (Soulsby, 1997). In this study, bedforms were always present and therefore calculations on shear-stress, friction velocity and Shields parameter related to suspended sediment profiles were calculated using a roughness of $z_{o}=\beta \eta(\eta / \lambda)$ (Soulsby, 1997) where $\beta=1$ was chosen as the default value, $\eta$ was the ripple height and $\lambda$ the ripple wavelength. The form drag shear-stress was typically an order of magnitude greater than the skin friction shear-stress. 


\subsection{Bedform measurements and predictions}

The ARP collected measurements of the bed profile along a $2 \mathrm{~m}$ transect every half hour over the 41.7 day deployment period and the results were presented in Fig. $2 \mathrm{f}$. These data have been analysed to extract ripple height, $\eta$, wavelength, $\lambda$, and steepness, $\eta / \lambda$. The results from this analysis are shown by the black line in Fig. 4 with estimates for the errors, given by the shaded region. In Fig. 4a the measured values for $\eta$ are presented with an error of $\pm 15 \%$; this shows a relatively stable background level of $\eta=0.02-0.04 \mathrm{~m}$ which increases during the periods of higher wave activity, peaking at around $0.17 \mathrm{~m}$ during passage of the first high wave event. The ripple wavelengths are shown in Fig. 4b. It has been assumed that the ripples were predominantly generated by the waves and therefore the ripple lengths measured with the ARP were reduced to account for the angle between the measured transect and the incoming wave direction. The shaded error region represents an uncertainty in this angle of $\pm 10^{\circ}$. The values for $\lambda$ are seen to have a background level of $0.2-0.3 \mathrm{~m}$ which increases at times of higher wave activity with maximum lengths of around $1.0 \mathrm{~m}$. In Fig. 4c ripple steepness and uncertainty are shown. Under low wave conditions steepness is seen to be relatively large and in the region $\eta / \lambda=0.1-0.2$, while during the higher wave events the ripples are tending to reduce in steepness having values of around 0.05-0.1. The average ripple height, wavelength and steepness over the deployment period were respectively $\langle\eta\rangle=0.035$ $\mathrm{m},\langle\lambda\rangle=0.32 \mathrm{~m}$ and $\langle\eta / \lambda\rangle=0.13$, where $<>$ is used to denote the time-average.

To compare the measurements with predictions, four wave ripple formulations were assessed: those of Grant and Madsen (1982) and Nielsen (1992) and the more recent works of Soulsby and Whitehouse (2005) and Pedocchi and Garcia (2009), which are based on larger data sets than the former two. It is worth noting at the outset that none of the formulations was able to fully capture the measured variability of $\eta, \lambda$, and $\eta / \lambda$ over the whole of the time series. 
Nielsen (1992) reproduced some of the features observed, but overall was a somewhat poorer predictor than the other three, therefore only the predictions from the other three formulations are presented here. Overall they provided reasonable agreement with the observations, yet at the same time illustrate how the different formulations can give contrasting predictions.

For Grant and Madsen (1982) the expression used was:

For $\theta_{c r}<\theta_{w} \leq \theta_{B}$

$\eta=0.22\left(\frac{\theta_{w}}{\theta_{c r}}\right)^{-0.16} A_{w}$

$\lambda=\eta /\left[0.16\left(\frac{\theta_{w}}{\theta_{c r}}\right)^{-0.04}\right]$

For $\quad \theta_{w}>\theta_{B}$

$\eta=0.48\left(D^{1.5} / 4\right)^{0.8}\left(\frac{\theta_{w}}{\theta_{c r}}\right)^{-1.5} A_{w}$

$\lambda=\eta /\left[0.28\left(D^{1.5} / 4\right)^{0.6}\left(\frac{\theta_{w}}{\theta_{c r}}\right)^{-1}\right]$

With

$\theta_{B}=1.8 \theta_{c r}\left(D^{1.5} / 4\right)^{0.6}$

Here, $\theta_{w}$ was obtained from skin friction component of $\tau_{w}$ and $\theta_{c r}$ from equation (9).

The formulation for Soulsby and Whitehouse (2005) predicts the normalised wavelength and the steepness:

$$
\begin{aligned}
& \frac{\lambda}{A_{w}}=\left[1+1.87 \times 10^{-3} \Delta\left(1-\exp \left\{\left(2 \times 10^{-4} \Delta\right)^{1.5}\right\}\right)\right]^{-1} \\
& \frac{\eta}{\lambda}=0.15\left[1-\exp \left\{-(5000 / \Delta)^{3.5}\right\}\right]
\end{aligned}
$$

where $\Delta$ is defined as $A_{w} / d_{50}$. Pedocchi and Garcia (2009) developed formulations for the normalised wavelength and height for fine $\left(d_{50}<170 \mu \mathrm{m}\right)$, medium $\left(170 \mu \mathrm{m}<d_{50}<220 \mu \mathrm{m}\right)$ and coarse sand size $\left(d_{50}>220 \mu \mathrm{m}\right)$ and the latter is used here for comparison: 
$\frac{\lambda}{A_{w}}=1.3\left[\left(0.05 U_{w} / w_{S}\right)^{2}+1\right]^{-1}$

$\frac{\eta}{A_{w}}=0.2\left[\left(0.055 U_{w} / w_{s}\right)^{3}+1\right]^{-1}$

The settling velocity was estimated following Soulsby (1997):

$w_{s}=\frac{v}{d_{50}}\left[\left(10.36^{2}+1.049 D^{3}\right)^{\frac{1}{2}}-10.36\right]$

As was shown in Fig. 3 there were times when the shear-stress was insufficient to mobilise the median sediment size. Therefore for the three ripple formulations when $\tau<\tau_{c}$ the ripple dimensions were deemed to remain unchanged with time and pre-existing dimensions were assumed until $\tau>\tau_{c}$ when new dimensions were calculated.

As can be seen in Fig. 4, all three formulations capture the general levels of $\eta, \lambda$, and $\eta / \lambda$, although some of the details, especially around the higher wave events, are not so well reproduced. In Fig. 4a the predictions for ripple height using Grant and Madsen (1982) (green line) compare quite well with the data, with the low and high wave conditions being reasonably well represented. Soulsby and Whitehouse (2005) predictions (red line) are comparable with the data during periods of low wave activity, however, the high wave events are not so well reproduced and for the first high wave event the prediction is for a reduction in ripple height, while the data show an increase. Interestingly the most recent predictions of Pedocchi and Garcia (2009) (blue line) give results that are very similar to Grant and Madsen (1982). The calculated mean values for ripple height, $\langle\eta\rangle$, are given by Soulsby and Whitehouse (2005) as $\langle\eta\rangle=0.028 \mathrm{~m}$, which marginally underestimates the observed value, while Grant and Madsen (1992), with $<\eta>=0.046 \mathrm{~m}$ and Pedocchi and Garcia (2009), with $<_{\eta}>=0.042 \mathrm{~m}$ are somewhat of an overestimate. In Fig. $4 \mathrm{~b}$ the formulations again generally 
reproduce the low wave ripple wavelengths, and as with the ripple height, it is Grant and Madsen (1982) and Pedocchi and Garcia (2009) that predict substantial increases in ripple wavelength for the higher wave events. The values for $\langle\lambda\rangle$ were underestimated by Soulsby and Whitehouse (2005), $<\lambda>=0.19 \mathrm{~m}$ and Pedocchi and Garcia (2009) with $<\lambda>=0.27 \mathrm{~m}$, while Grant and Madsen (1982) overestimated the value, $<\lambda>=0.43 \mathrm{~m}$. Shown in Fig. $4 \mathrm{c}$ are the steepness predictions, these do not show the variability observed in the data and only marginally capture the reduction in steepness observed at the higher wave events. However, the mean steepness is comparable with the observations giving values of; Grant and Madsen (1982), $\langle\eta / \lambda>=0.15$, Soulsby and Whitehouse (2005), $\langle\eta / \lambda>=0.15$, and Pedocchi and Garcia (2009), $\langle\eta / \lambda>=0.16$. In general, the three predictors worked reasonably well at predicting ripple height and length in low wave conditions, with Grant and Madsen (1982) and Pedocchi and Garcia (2009) capturing the higher wave events better and with all formulations having similar steepness, which, though comparable with the measured mean steepness over the deployment period, do not reflect the variability observed in the data.

\subsection{Reference concentrations}

Reference concentrations obtained from the ABS were compared with two commonly used empirical models, namely Lee et al. (2004) and Nielsen (1986). Both formulations have proved to be reasonably successful in previous studies (Green and Black, 1999; Grasmaijer and Kleinhans, 2004). Following Lee et al. (2004) the reference concentration, $C_{l}$, was calculated as follows:

$C_{l}=A\left[\theta_{\max } \frac{u_{* \max }}{w_{s}}\right]^{B}$ 
where $C_{l}$ is defined at a reference height, $z_{l}=0.01 \mathrm{~m}$ above the bed, in $\mathrm{kgm}^{-3}$. The two empirically derived constants were $A=2.58 \pm 1.7$ and $B=1.45 \pm 0.04$. Here, $\theta_{\max }$ and $u *_{\max }$ were obtained from the skin friction component of $\tau_{\max }$ output from equation (6). The value for $w_{s}$ was obtained using equation (13) with $d_{50}$ of the bed sediments used for the particle size. The formulation was derived using data sets from three coastal field sites under a wide range of wave conditions and with the median sand sizes of the bed ranging from $120 \mu \mathrm{m}$ to $350 \mu \mathrm{m}$. This size range covers the sediments encountered at the location of F3. The result from the three study sites showed a good fit to the data, with $90 \%$ of the predictions lying within $20 \%$ of the observations.

The reference concentration as derived by Nielsen (1986), $C_{n}$, is given by:

$$
C_{n}=\delta \rho_{s} \theta_{r}^{3}
$$

where $\delta=5 \cdot 10^{-3}$ in Nielsen's formulation. $\theta_{r}$ is the enhanced Shields parameter for a rippled bed, which is related to $\theta_{w}$ as follows:

$$
\theta_{r}=\frac{\theta_{w}}{(1-\pi \eta / \lambda)^{2}}
$$

Nielsen's expression was formulated using data based on waves alone, however, since in the present study wave shear-stress was dominant when sediments were mobile, the results were similar whether $\theta_{w}$ or $\theta_{\max }$ (see Fig. 3) was used in the calculation for the reference concentration. Nielsen used the ripple crest as the reference height for $C_{n}$ and therefore the ABS data were extrapolated to the bed for comparison with Nielsen's formulation. The extrapolated concentration at the bed was typically $40 \%$ greater than that measured at $0.01 \mathrm{~m}$ above the bed. 
As can be seen in equation (14) and (15) both the expression of Lee et al. (2004) and Nielsen (1986) are strongly related to $u *$, since $\theta \propto u_{*}$, with the former dependent on $\left(u_{* \max }\right)^{4.5}$ and the latter $\left(u *_{w}\right)^{6.0}$ and they also both have a scaling constant, $A$ or $\delta$, to match the predictions to the data. The main difference in the expressions is the very strong dependence of Nielsen's formulation for $C_{n}$ on the ripple steepness, $(1-\pi \eta / \lambda)^{-6}$. This strong dependence on ripple steepness has recently been questioned by Dolphin and Vincent (2009), who did not observe such sensitivity in a field study on bedforms and suspended sediments off the Dutch coast.

Fig. 5 shows the results of a comparison of the formulations of Lee et al. (2004) and Nielsen (1986) with the observed reference concentrations measured using the concentration profile and bed location obtained from the ABS. Again the black line represents the data with a grey region representing uncertainty ( \pm 1 standard deviation) derived from the ABS concentrations at each of the three frequencies. As can be seen in the figure the measurements for the reference concentration during the times of low wave activity varied with the tidal elevation. However, this was not due to stirring by tidal currents, but resulting from low waves impacting more effectively on the bed at low water and thereby generating larger values for the reference concentration. During the periods of high wave activity there is seen to be significant increases in the reference concentration with peak values in the region of $1.0 \mathrm{~kg}$ $\mathrm{m}^{-3}$. In Fig. 5a is shown a comparison of the Lee et al. (2004) (blue line) formulation for the reference concentration at $0.01 \mathrm{~m}$ above the bed with the data. This shows good agreement with the observations, having a time history which has very similar temporal trends to the data and magnitudes which are generally close to those measured. The correlation coefficient for the two data sets was $r^{2}=0.76$, with the temporal mean over the whole data set, $\left\langle C_{l}>\right.$, having predicted and observed values respectively of $0.11 \mathrm{~kg} \mathrm{~m}^{-3}$ and $0.077 \mathrm{~kg} \mathrm{~m}^{-3}$. In Fig. $5 \mathrm{~b}$ 
are shown two comparisons of Nielsen (1986) values of $C_{n}$, referenced to the bed location $z_{n}=0 \mathrm{~m}$. The first plot (blue line) used the measured values for $\langle\eta / \lambda\rangle$ in the evaluation of equation (16) and shows reasonable agreement during the high wave events, however there are long sections in the periods of low wave activity when the reference concentration is significantly overestimated. Comparison of the $\left\langle C_{n}>\right.$ predictions with observations gave 5.62 $\mathrm{kg} \mathrm{m}^{-3}$ and $0.11 \mathrm{~kg} \mathrm{~m}^{-3}$ respectively and $r^{2}=0.11$, which reflects the poor agreement between predictions and observations during conditions of low wave activity. The predictions using the steepness from the model of Pedocchi and Garcia (2009) overestimated the reference concentration, however it had a temporal structure very comparable with the data, and reducing Nielsen's constant value $\delta=5 \cdot 10^{-3}$ by an order of magnitude to $\delta=5 \cdot 10^{-4}$ gave the results presented in Fig. 5b (red line). The Nielsen (1986) predictions now compare favourably with the observations for the whole record with $r^{2}=0.81$ and $<C_{n}>=0.11 \mathrm{~kg} \mathrm{~m}^{-3}$; a result which is very comparable to that of Lee et al. (2004). The reduction in $\delta$ agrees, qualitatively, with Thorne et al. (2002) who found that $\delta=2.5 \cdot 10^{-3}$ gave a better fit to their data.

The comparisons presented here clearly show that the formulation of Lee et al. (2004) is a reasonable predictor of reference concentrations in the environment encountered in the present study. This result may be somewhat surprising given that the Lee et al. (2004) expression has no explicit representation for bedforms, however bedforms are implicitly accounted for in fitting the regression coefficients $A$ and $B$ to the data in their study. The results also indicate that it is problematic as to whether accounting for the detailed temporal variability in bedforms in Nielsen's (1986) formulation has any significant advantage, since the nominally constant steepness from Pedocchi and Garcia (2009), with $\delta=5 \cdot 10^{-4}$, provided a much more favourable comparison with the observed $C_{n}$. The lack of measured variability in 
$C_{n}$ with ripple steepness would seem somewhat counter-intuitive, given that detailed studies of sediment entrainment show that bedforms are important in understanding the underlying processes (Thorne et al., 2009; Grasmeijer and Kleinhans, 2004), however, recently Dolphin and Vincent (2009) concluded from field measurements of reference concentrations that measurements of bedform type did not help in predicting the value of $C_{n}$.

\subsection{Sediment concentration profiles}

The form of the sediment concentration profile with height above the bed is commonly represented by semi-empirical formulations. Among the most common shape functions used to describe concentration profiles under currents and waves (Soulsby, 1997) are the exponential, power law and Rouse profiles, with the latter being approximated by the power law in the bottom $25 \%$ of the water column. In the present study, the observations were made within the first metre above the bed in a mean water depth of $4.5 \mathrm{~m}$, and therefore the exponential and power law formulations are compared here with the observations.

The power law shape function comes from the advection-diffusion theory, which represents the balance between the downward transport of sediment due to settling under gravity and the upward transport by turbulent processes, and has the form:

$\Psi_{p}(z)=\left(z / z_{r}\right)^{-P}$

where $z$ is the height above the bed, the Rouse parameter, $P=w_{s} / \kappa u *_{\max }$ and $\kappa=0.4$ is the von Karman constant. $z_{r}$ is the reference height at which the reference concentration is given. Provisionally, a single particle size, $d_{50}$ of the bed, was used to estimate the settling velocity. However, we also considered the reduction of the particle size of sediments in suspension. As 
before, $u *_{\max }=\sqrt{\tau_{\max } / \rho}$, however the form drag was used to calculate $\tau_{\max }$ using $z_{o}=\eta(\eta / \lambda)$. If $\tau_{\max }$ had been calculated using only the skin friction component of shear-stress, calculated concentration profiles would have been reduced by more than two orders of magnitude with increasing height above the bed.

The exponential shape function takes the form (Nielsen, 1984; Nielsen, 1992):

$$
\Psi_{L}(z)=e^{-z / L_{s}}
$$

where $z$ is height above the bed and $L_{s}$ is a vertical decay length scale defined by Nielsen (1992) as:

$$
\begin{array}{lll}
L_{s}=\frac{0.75\left(A_{w} \omega_{p} \eta\right)}{w_{s}}, & \frac{A_{w} \omega_{p}}{w_{s}}<18 \\
L_{s}=1.4 \eta, & \frac{A_{w} \omega_{p}}{w_{s}} \geq 18
\end{array}
$$

The Nielsen formulation is often ascribed to suspension profiles generated by a vortex entrainment process with uniform sediment diffusivity and applicable for about $2 \eta-4 \eta$ above the bed (Thorne et al., 2009).

Fig. 6 shows a comparison of two ABS profiles of suspended sediment collected during the first high wave event. The symbols represent the mean value and the shaded region the uncertainty by \pm 1 standard deviation. The measurements in Fig. 6a illustrate an exponential profile fitted to the data; this shows good agreement within approximately $0.2 \mathrm{~m}$ of the bed, which was around $2 \eta-3 \eta$; above this height there is some departure of the exponential from the ABS profile. Fig. $6 \mathrm{~b}$ shows a profile which conformed more closely to a power law profile and there is good agreement between the line fitted using the power law and the data 
up to $0.5 \mathrm{~m}$ above the bed. In the following analysis we aim to assess which shape function, either exponential or power law, is best fitted to the ABS profiles of suspended concentration and how well do predictions of $L_{s}$ and $P$ compare with the measured values obtained from the gradients of the concentration profiles with height above the bed.

To assess the exponential and power law shape function fits to the ABS concentration profiles, the correlation coefficient, $r^{2}$, was used as the metric of goodness of agreement between the fitted profile and the measurements. For each concentration profile, both formulations were fitted to the data over a height above the bed that range from $0.04 \mathrm{~m}-0.6$ $\mathrm{m}$ in $0.02 \mathrm{~m}$ step intervals. This was carried out over the 1000 profiles and the average was taken to provide $\left\langle r^{2}>\right.$ for the deployment period. The results are shown in Fig. 7 also with the standard deviation. Applying a Wilcoxon rank sum test, it was found that the mean values, $<r^{2}>$, were significantly different between the exponential and power law fits. Generally, there is seen to be an overall reduction in $\left\langle r^{2}\right\rangle$ as the height over which the formulation are fitted to the data increases, which indicates that neither formulation fully represents the data over the whole profile. Both formulations are seen to fit the measured concentration profiles equally well up to around $0.2 \mathrm{~m}$ above the bed, although the power law correlation coefficient was marginally higher. Above $0.2 \mathrm{~m}$ the values for $\left\langle r^{2}\right\rangle$ begin to diverge and the results for the exponential fit fall off more rapidly with height above the bed than that of the power law. The reduced fit with height above the bed for the exponential formulation is probably not too surprising, as its region of applicability is within a constant diffusivity layer considered to be of the order of $2 \eta-4 \eta \mathrm{m}$ above the bed. The power law fit to the data retains a relatively high coefficient up to $0.5 \mathrm{~m}$ above the bed with $r^{2} \geq 0.8$. The comparison of the two formulations, with the data collected in the present study, indicates that, in a coastal sandy environment with waves and currents (although in this study waves were dominant), the power law 
generally provided the better fit to the data. This observation is consistent with the field measurements reported by Dolphin and Vincent (2009). The laboratory observations of van de Werf et al. (2006) under waves found that concentration profiles within $2 \eta$ of the bed were better represented by an exponential profile, although the difference was small, with the exponential fit having a value of $r^{2}=0.964$ and power law profile fits having $r^{2}=0.947$. However, their data departed significantly from an exponential form above $2 \eta$ and a power law shape factor provides a better representation of their data above this height.

Although the results in Fig. 7 indicate that a power law shape function fit to the data over the bottom $0.5 \mathrm{~m}$ above the bed is the better of the two commonly used empirical formulations, it does not provide any assessment of our capability to predict the values of $L_{s}$ or $P$. Using the gradient of the exponential and power law fits to the measured concentration profiles, values of $L_{s}$ and $P$ were obtained and the results are shown in Fig. 8. The measurements are again given by the black line, with shaded area of uncertainty, which was obtained by fitting the shape functions to the data from the bed to heights between $z=0.1-0.3 \mathrm{~m}$. To compare predictions with observations, $P$ was calculated using $P=w_{s} / \kappa u *_{\text {max }}$, where $u_{* \max }$ was calculated using the form drag shear-stress with $z_{o}=\eta(\eta / \lambda)$ using the measured ripple dimensions and $w_{s}$ was obtained from equation (13) with $d_{50}=255 \mu \mathrm{m}$. For $L_{s}$, the predicted values were calculated using equations (19a) and (19b), using the measured values for $A_{w}, \omega$ and $\eta$. The results are shown by the red lines in Fig. $8 \mathrm{a}$ and $8 \mathrm{~b}$. Focusing initially on the comparison of $P$, a quick inspection of Fig. 8a would suggest relatively poor agreement. However, closer examination shows that, at periods of high wave activity, when suspended concentrations are high, the predictions are comparable with the observations and it is the quiescent background low concentration periods where the disagreement is greatest. The results for the comparison for $L_{s}$ are shown in Fig. $8 \mathrm{~b}$ and the same trend is seen, with $L_{s}$ 
being comparable to the observations at the high wave events and in much poorer agreement during the low wave conditions. Under low waves the predicted values for $P$ are much larger than the observed, while for $L_{s}$, the predicted vertical mixing length is much smaller than the observed. The observed values for $P$ and $L_{s}$ indicate that the suspended sediment concentrations are more uniform with height above the bed than predicted for periods of low waves. The LISST on F3 measured particle size and concentration, however, the time history of the suspended concentration data from the LISST, located at $0.99 \mathrm{~m}$ above the bed, did not correlate well with the bed shear-stress, possibly due to weak coupling between pick-up and suspended sediments at $0.99 \mathrm{~m}$ height above the bed. Therefore the LISST data was only used to provide an estimate of $d_{50}$ for the suspended sediments at $0.99 \mathrm{~m}$ above the bed. This was typically in the range $50 \mu \mathrm{m}-120 \mu \mathrm{m}$, which was much smaller than the $d_{50}$ of the bed. It could be argued that during the low wave periods, with weak flows, it was the finer material from the bed that was being entrained locally or advected through the system and generating suspended concentration profiles which were more uniform than those predicted using $d_{50}$ of the bed. Therefore, using the LISST observations as a guide to the background particle size, calculations for $P$ and $L_{s}$ were repeated using $d_{50}=100 \mu \mathrm{m}$ to show the impact of changes in suspended sediment size. The results shown by the green lines are in better agreement with the measurements, especially the values for $P$, during the low wave periods. Merging together the predictions, using $d_{50}=255 \mu \mathrm{m}$ during the high wave events and $d_{50}=100 \mu \mathrm{m}$ during low wave periods, gives the final predicted values shown by the blue lines presented in Fig. 8c and 8d. This shows much improved agreement for $P$ over the whole time series and some marginal improvement in $L_{s}$. In the latter case, during low wave conditions, it may have been that vortex entrainment was not the dominant suspension mechanism, hence the suspended concentration profile was probably not being scaled by $L_{s}$. 


\subsection{Prediction of suspended sediment concentration profile time series}

Fig. 9 presents comparisons of predictions of suspended sediment concentration with measurements. In Fig. 9a are ABS measurements of suspended sediment concentration profiles in the bottom $0.5 \mathrm{~m}$ above the bed over the 41.7 day deployment. The predicted suspended sediment concentration profiles are shown in Fig. 9b and 9d. In both cases the Lee et al. (2004) formulation was used to obtain the reference concentration, and the power law shape function was used to represent the variation in the suspended concentration with height above the bed. In Fig. 9b, $P$ was calculated using $u *_{\text {max }}$, with $z_{o}$ estimated from the measured ripple height and steepness, and with $w_{s}$ based on $d_{50}=255 \mu \mathrm{m}$ during the high wave events, and $d_{50}=100 \mu \mathrm{m}$ during quiescent conditions. The results show comparable time series structures both in magnitude, duration and height over the vast majority of the deployment period. A quantitative comparison between the observations in Fig. 9a and predicted in Fig. $9 \mathrm{~b}$ is presented in Fig. 9c. This uses a normalised difference, $\left.\left(\left\langle C_{P}\right\rangle-\left\langle C_{a}\right\rangle\right) /<C_{a}\right\rangle$, as the metric of comparison, $C_{p}$ is the predicted suspended concentration and $C_{a}$ is the measurements from the $\mathrm{ABS}$ and, as before, $<>$ indicates a time average over the high and low wave condition periods. This metric was calculated for each $0.01 \mathrm{~m}$ height above the bed and separated into low wave conditions and high wave events. The results show that, up to a height of $0.1 \mathrm{~m}$ above the bed, the predictions fall within $30 \%$ of the observed suspended concentration and this increased to a maximum value of $60 \%$ for the whole suspended concentration profile. This is considered to be reasonable agreement given present modelling capability (Davies et al., 2002; Cacchione et al., 2008).

It was considered interesting to ascertain how well the predictions would have performed without access to the ripple measurements and using a constant value for $d_{50}$. The results are 
show in Fig. 9d where $P$ was calculated using the predictions of Pedocchi and Garcia (2009) to estimate ripple height and steepness and hence $z_{o}$ and $d_{50}=255 \mu \mathrm{m}$ for both low and high wave events. The concentrations near the bed in Fig. 9d appear quite similar to those in Fig. $9 \mathrm{~b}$, as expected, because both have the same time series reference concentration, however, there is increasing divergence with height above the bed, as shown by the normalised difference metric in Fig. 9e. The difference during high wave events is comparable to those in Fig. 9c within the first $0.1 \mathrm{~m}$, however, above $0.1 \mathrm{~m}$, the difference increases to $120 \%$. For low wave conditions a steady increase in difference is observed with height above the bed with values around $-100 \%$ at $0.5 \mathrm{~m}$. From the percentage difference analysis shown in Figs 9c and $9 \mathrm{e}$, it is clear that the measurements of bedforms, and accounting for suspended particle size variability, improves the agreement between predictions and observations and therefore it suggests that such measurements should necessarily be routinely collected. 


\section{Conclusions}

This paper has presented a data set containing simultaneous measurements of the hydrodynamics, the suspended sediments and the bedforms collected within a coastal embayment protected by shore parallel breakwaters. The observations were made over a 41.7 day period and included spring-neap tidal cycles and periods of low and high wave activity. From the measurements, derived parameters of shear-stress, bedform dimensions, reference concentration and suspended concentration profiles were obtained. These parameters have been compared with predicted values, calculated using semi-empirical formulations commonly employed in sandy coastal environments. The output from the comparison has provided an analysis of the performance capability of the formulations examined and some recommendations for suitable predictors to be used in similar environments to the one studied here.

The shear-stress is one of the main drivers in many sediment transport formulations. In the present study the methodology of Soulsby and Clark (2005) was employed using pressure and velocity measurements collected using an ADV outside the wave boundary layer. Estimates were obtained for the skin friction shear-stress for the currents alone, waves alone and combined wave-current maximum shear-stress. The results showed that the skin friction shear-stress was dominated by wave events and weak wave-current interactions were observed. The skin friction shear-stress was used in the predictions of bedform dimensions and for the reference concentration. For making predictions of suspended sediment profiles, the shear-stress due to form drag, and based on the ripple dimensions, was used; this was typically an order of magnitude greater than the skin friction. 
Measurements of the bedforms were collected using an acoustic ripple profiler. The bedform dimensions derived from the ARP were relatively stable during low wave conditions with ripple heights around $0.03 \mathrm{~m}-0.05 \mathrm{~m}$ and wavelengths $0.2 \mathrm{~m}-0.4 \mathrm{~m}$. During high wave events, larger features appeared, with the ripple height peaking at about $0.15 \mathrm{~m}$ and wavelength of the order of $1.0 \mathrm{~m}$. A comparison of three model predictions with the observations was presented. All the models compared favourably with the data during low wave periods, however, during the high wave events, the Soulsby and Whitehouse (2005) method tended to wash out the bedforms and thereby failed to capture the observed increase in ripple height and wavelength. All three models gave a nominally similar constant ripple steepness for most of the recorded period with some reduction during the high wave events. None of the models fully captured the observed changes in ripple steepness. From the present field study the predictions of Grant and Madsen (1982) and Pedocchi and Garcia (2009) provided the more consistent comparisons with the observations.

The reference concentrations were obtained from the ABS profiles. These data were compared with the commonly used expressions of Nielsen (1986), for wave dominated environments, and the more recent formulation of Lee et al. (2004). The main difference between the two approaches is that the Nielsen (1986) expression explicitly accounts for the impact of flow enhancement over the ripple crest by including the ripple steepness. Comparing the two predictions with the observations showed that the formulation of Lee et al. (2004) out-performed that of Nielsen (1986), although a modified Nielsen calculation, with nominally constant steepness and $\delta=5 \cdot 10^{-4}$, did compare as well with the observations as Lee et al. (2004). The indication from the present study, and those of Lee et al. (2004), Grasmeijer and Kleinhans (2004) and Dolphin and Vincent (2009), indicate that the reference 
concentration may not be as strongly coupled to the ripple steepness as suggested by Nielsen (1986).

Comparison of exponential and power law profiles of suspended sediment concentration showed comparable correlation coefficients when fitted to the data in the bottom $0.2 \mathrm{~m}$ above the bed, while at greater heights above the bed the power law provided the better fit. Comparison of the predicted values, for Nielsen's (1992) mixing length, $L_{s}$, and the power law Rouse parameter, $P$, showed moderately good agreement with the data during the high wave events, but much poorer agreement during low wave conditions. The discrepancy during low wave conditions was ascribed to a reduction in particle size in suspension due to some differential entrainment or advection and an adjustment of the $d_{50}$ in suspension from the bed median size of $255 \mu \mathrm{m}$ to $100 \mu \mathrm{m}$ significantly improved the agreement between the predicted Rouse parameter and the observations.

In this study, the mobilisation of the bed was deemed to be determined by the skin friction shear-stress, while the shear-stress associated with form drag was considered to control the subsequent entrainment process of sediments away from the bed up into the water column. The skin friction was therefore used in the prediction of the bedforms themselves. For the prediction of the reference concentration the skin friction shear-stress was also employed, however, for Nielsen (1986) the shields parameter derived from the skin friction shear-stress was modified to account for the presence of bedforms. There is no such explicit bedform dependence in the predictions of Lee et al (2004), although it is highly likely their data contained bedforms and their resulting expression, with fitted constants, implicitly incorporates bedform effects on reference concentration. It is suggested from the present analysis that the temporal structure of the reference concentration is highly dependent on the skin friction shear-stress, while its dependence on ripple steepness may be somewhat weaker 
than the sixth power formulated by Nielsen (1986). For the entrainment of sediments up into the water column accounting for the presence of the bedforms was essential. Although not detailed in the text, using the skin friction rather than the form drag to calculate the bed shearstress gave values for $P$ which substantially reduced the predicted suspended load. This prediction compared much more poorly with the observed data than that using a shear-stress based on the form drag; this clearly illustrates the accepted linkage between bedforms and suspended sediment concentrations levels.

Finally, the analysis presented here, using the Lee et al. (2004) reference concentration calculated with the skin friction shear-stress, the power law shape function, measured ripple dimensions to estimate total bed shear-stress and accounting for variability in particle size, resulted in predicted and measured suspended concentration profiles which were very comparable in terms of magnitude and structure for the majority of the observational period. Using calculated bedforms with a fixed particle size showed a noticeable degradation in the comparison; thereby indicating the value of accurate bedform and suspended particle size data when assessing sediment formulations used in nearshore sandy coastal environments. 


\section{Acknowledgements}

The LEACOAST2 project, funded by EPSRC, UK, provided the data. Additional support was provided by the NERC FORMOST project and the EU MICORE project. The authors thank Dr. Paul Bell, Dr. Richard Cooke, the NOC diving team and the Ocean Technology Group at NOC for their contributions to the field campaign. The sediment group at the University of East Anglia, UK, including Professor Christopher Vincent, Dr. Tony Dolphin and Dr. John Bacon were part of the LEACOAST study and are thanked for their logistic support. Professor Alan Davies and Dr. Jonathan Malarkey from Bangor University, UK, provided many helpful comments, suggestions and continuous encouragement. 


\section{References}

Amoudry L.O. and Souza, A., 2011. Deterministic coastal morphological and sediment transport modelling. A review and discussion. Rev. Geophys. 49, RG2002, doi:10.1029/2010RG000341.

Biron, P.M., Robson, C., Lapointe, M.F., and Gaskin, S.J., 2004. Comparing different methods of bed shear stress estimates in simple and complex flow fields. Earth Surf. Proc. Land. 29, 1403-1415.

Cacchione, D.A., Thorne, P.D., Agrawal, Y., Nidzieko, N.J., 2008. Time-averaged near-bed suspended sediment concentrations under waves and currents: Comparison of measured and model estimates. Cont. Shelf Res. 28, 470-484.

Crawford, A.M., and Hay, A.E., 1993. Determining suspended sand size and concentration from multifrequencyacoustic backscatter. J. Acoust. Soc. Am. 94, 3312-3343.

Davies, A.G., van Rijn, L.C., Damgaard, J.S., van de Graaff, J., Ribberink, J.S., 2002. Intercomparison of research and practical sand transport models. Coast. Eng. 46, 1-23.

Davis, J.P., Walker, D.J., Townsend, M., and Young, I.R., 2004. Wave-formed sediment ripples. Transient analysis of ripple spectral development. J. of Geophy. Res. 109. C07020, doi:10.1029/2004JC002307.

Dolphin, T., and Vincent, C.E., 2009. The influence of bed forms on reference concentration and suspension under waves and currents. Cont. Shelf Res. 29, 424-432.

Goring, D.G., and Nikora, V.I., 2002. Despiking acoustic Doppler velocimeter data. J. Hydr. Eng. 128, 117-126.

Grant, W.D and Madsen, O.S., 1982. Movable bed roughness in unsteady oscillatory flow. J. Geophys. Res. 87(C1), 469-481.

Grasmeijer, B.T., and Kleinhans, M.G., 2004. Observed and predicted bed forms and their effect on suspended sand concentrations. Coast. Eng. 51, 351-371. 
Green, M.O., 1992. Spectral estimates of bed shear stress at subcritical reynolds numbers in a tidal boundary layer. J. Phys. Ocean. 22, 903-917.

Green, M.O., and Black, K.P., 1999. Suspended-sediment reference concentration under waves: field observations and critical analysis of two predictive models. Coast. Eng. $38,115-141$.

Holmedal, L.E., and Myrhaug, D., 2004. Bed load transport under irregular waves plus current from Monte Carlo simulations of parameterized models with application to ripple migration rates observed in the field. Coast. Eng. 51, 155-172.

Hurther D. and Thorne P.D., 2011. Suspension and near-bed load sediment transport processes above a migrating, sand-rippled bed under shoaling waves. J. Geophys. Res. 116, C07001, doi:1029/2010JC006774.

Hurther, D, Thorne PD, Bricault M, Lemmin L and Baroud J., 2011. A multi-frequency acoustic concentration and velocity profiler (ACVP) for boundary layer measurements of fine-scale flow and sediment transport processes. Coast. Eng. 58, 294-605, doi 10.1016/j.coastaleng.2011.01.006.

Kim, S.C., Friedrichs, C.T., Maa, J.P.Y., and Wright, L.D., 2000. Estimating bottom stress in tidal boundary layer from acoustic doppler velocimeter data. J. Hydraul. Eng. 126, $399-406$.

Krogstad, H.E., 1991. Reliability and resolution of directional wave spectra from heave, pitch and roll data buoys, in Beal, R.C., ed., Directional wave spectra, Johns Hopkins University Press, pp. 66-71.

Lee, G., Dade, W.B., Friedrichs, C.T., and Vincent, C.E., 2004. Examination of reference concentration under waves and currents on the inner shelf. J. Geophys. Res. 109. C02021, doi:10.1029/2002JC001707. 
Nielsen P., 1984. On the motion of suspended sand particles. J. Geophys. Res. 89(C1), 616626.

Nielsen, P., 1986. Suspended sediment concentration under waves. Coastal Eng. 10, 23-31.

Nielsen, P., 1992. Coastal bottom boundary layers and sediment transport. World Scientific, Advanced Series on Ocean Engineering, 4, pp. 324.

Nielsen, P., 2009. Coastal and estuarine processes. World Scientific, Advanced Series on Ocean Engineering, 29, pp. 343.

Noyes, R., 2007. An investigation into bedforms and sediment parameters and inferred bed roughness around the shore parallel reef system at Sea Palling. Master degree thesis. University of East Anglia, UK. pp. 44.

Pan, S., Reeve, D., Davidson, M., O'Connor, B., Vincent, C., Dolphin, T., Wolf, J., Thorne, P., Bell, P., Souza, A., Chesher, T., Johnson, H. and Leadbetter, A., 2011. Largerscale morphodynamic impacts of segmented shore-parallel breakwaters on coasts and beaches: an overview of the LEACOAST2 project. J. Ame. Shor. Beach Preserv. Associa. 78(4), 35-45.

Pedocchi, F. and Garcia, M.H., 2009. Ripple morphology under oscillatory flow: 1. Prediction. J. Geophy. Res. 114, C12014, doi:10.1029/2009JC005354.

Ribberink, J. and Al-Salem, A., 1994. Sediment transport in oscillatory boundary layers in cases of rippled beds and sheet flow. J. Geophys. Res. 99(C), 12707-12727, doi:10.1029/94JC00380.

Soulsby, R.L., 1997. Dynamics of marine sands. London, UK. Thomas Telford, pp. 249. Soulsby, R.L., and Clarke, S., 2005. Bed shear-stress under combined waves and currents on smooth and rough beds. HR Wallingford, Internal Report. Report 137. pp. 52. 
Soulsby, R.L., Hamm, L., Klopman, G., Myrhand, D., Simons, R.R. and Thomas, G.P., 1993. Wave-current interactions within and outside the bottom boundary layer. Coast. Eng. 21, 41-69.

Soulsby, R.L., and Whitehouse, R., 2005. Prediction of ripple properties in shelf seas. HR Wallingford, Internal Report, Report TR 154, pp. 99.

Thorne, P.D., and Campbell, S.C., 1992. Backscattering by a suspension of spheres. J. Acoust. Soc. Am. 92, 978-986.

Thorne, P. D., Davies, A. G. and Bell, P. S., 2009. Observations and analysis of sediment diffusivity profiles over sandy rippled beds under waves. J. Geophys. Res. 114, C02023, doi:10.1029/2008JC004944.

Thorne, P.D., and Hanes, D.M., 2002. A review of acoustic measurements of small-scale sediment processes. Cont. Shelf Res. 22, 603-632.

Thorne, P.D., and Hardcastle, P.J., 1997. Acoustic measurements of suspended sediments in turbulet currents and comparison with in-situ samples. J. Acoust. Soc. Am. 101, 26032614.

Traykovski, P., 2007. Observations of wave orbital scale ripples and nonequilibrium timedependent model. J. Geophys. Res. 112. C06026, doi:10.1029/2006JC003811.

van der Werf, J.J., Ribberink, J.S., O'Donoghue, T., and Doucette, J.S., 2006. Modelling and measurement of sand transport processes over full-scale ripples in oscillatory flow. Coast. Eng. 53, 657-673.

van Rijn, L.C., 1984. Suspended transport, part II: Suspended load transport. J. Hydrol. 110, $1613-1641$.

Wahl, T.L., 2003. Discussion of "Despiking acoustic doppler velocimeter data". J. Hydraul. Eng. 129, 484-486. 
Williams, J.J., Bell, P.S., and Thorne, P.D., 2005. Unifying large and small wave-generated ripples. J. Geophys. Res. 110, C02008, doi:10.1029/2004JC002513.

Wolf, J., 1997. The analysis of bottom pressure and current data for waves. 7th International Conference on Electronic Engineering in Oceanography, 439, Southampton, p. 165169.

Wolf, J., Souza, A.J., Bell, P.S., Thorne, P.D., Cook, R.D., and Pan, S., 2008. Wave, currents and sediment transport observed during the LEACOAST2 experiment. Physics of estuaries and coastal seas. Liverpool, UK., p. 373-376.

Young, R.A., Merrill, J.T., Clarke, T.L., and Proni, J.R., 1982. Acoustic profiling of suspended sediments in the marine bottom boundary layer. Geophys. Res. Lett. 9, $175-178$. 


\section{Figure captions}

Fig. 1. a) Location of Sea Palling, UK. b) The position of measurement frame F3, the shore parallel breakwaters and the depth contours. c) The instrumentation on frame F3 was an Acoustic Doppler Velocimeter (ADV), an Acoustic Backscatter System (ABS), an Acoustic Ripple Profiler (ARP), and a Laser In-Situ Scattering and Transmissometry (LISST).

Fig. 2. Time series of: a) water depth, b) current velocity components, c) significant wave height, $H_{s}$, d) peak wave period, $T_{p}$, e) ABS suspended sediment concentration (colour scale in $\left.\log _{10}\left(\mathrm{kgm}^{-3}\right)\right)$ and $\mathrm{f}$ ) bed profile (colour scale in $\mathrm{m}$ ).

Fig. 3. Bottom skin friction shear-stresses estimated using Soulsby and Clarke (2005) formulation for current alone, $\tau_{c}$, waves alone, $\tau_{w}$, and maximum wave-current, $\tau_{\max }$. The horizontal line is the threshold shear-stress for the initiation of movement for $d_{50}$ of the bed.

Fig. 4. Time series comparison of ripple a) height, b) wavelength and c) steepness, measured with an uncertainty band and predicted G\&M (Grant and Madsen, 1982), S\&W (Soulsby and Whitehouse, 2005) and P\&G (Pedocchi and Garcia, 2009).

Fig. 5. Comparison of the time series measurements of the reference concentration including an uncertainty band with: a) Lee et al. (2004) predictions at $z=0.01 \mathrm{~m}$, b) Nielsen (1986) predictions at the bed, $z=0 \mathrm{~m}$ using the observed ripple steepness with $\delta=5 \cdot 10^{-3}$ (blue line) and using the predicted ripple steepness from Pedocchi and Garcia (2009) with $\delta=5 \cdot 10^{-4}$ (red line). 
Fig. 6. Measured suspended sediment concentration profiles, $C$, with height above the bed, $z$, obtained from the ABS $(\bullet)$ with an uncertainty band. Comparison of the two measured profiles with shape functions; a) exponential and b) power law.

Fig. 7. Mean correlation coefficient $\left\langle r^{2}\right\rangle$ and its standard deviation with height, $z$, above the bed, between the data and exponential (o) and power law ( + ) shape functions.

Fig. 8. Comparison of the time series measurements with an uncertainty band and predicted $P$ and $L_{s}$. a) $P$ and b) $L_{s}$ both calculated using $d_{50}=255 \mu \mathrm{m}$ (red line) and $d_{50}=100 \mu \mathrm{m}$ (green line). c) $P$ and d) $L_{s}$ calculated with $d_{50}=255 \mu \mathrm{m}$ for the high wave events and $d_{50}=100 \mu \mathrm{m}$ for low wave periods.

Fig. 9. Time series of the suspended sediment concentration profiles. a) Concentration measured using the ABS. b) Predicted using the Lee et al. (2004) reference concentration with $P$ calculated using a friction velocity with $z_{o}$ based on the measured ripple dimensions and variable sediment size and c) the normalised difference for high and low wave conditions. d) Predicted using the Lee et al. (2004) reference concentration with $P$ calculated using a friction velocity with $z_{o}$ based on Pedocchi and Garcia (2009) ripple dimensions and constant sediment size, and e) the normalised difference. 

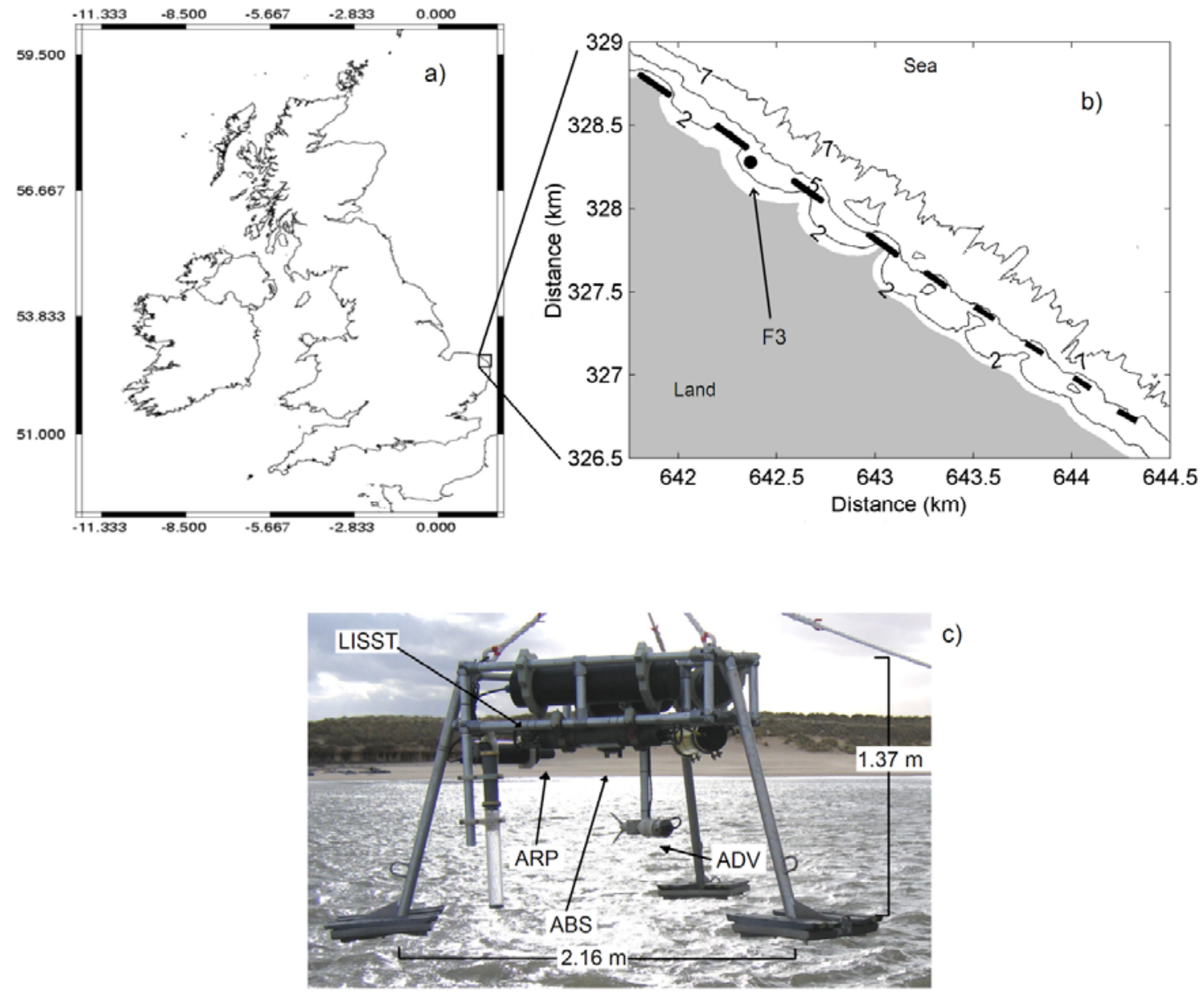

Fig. 1 

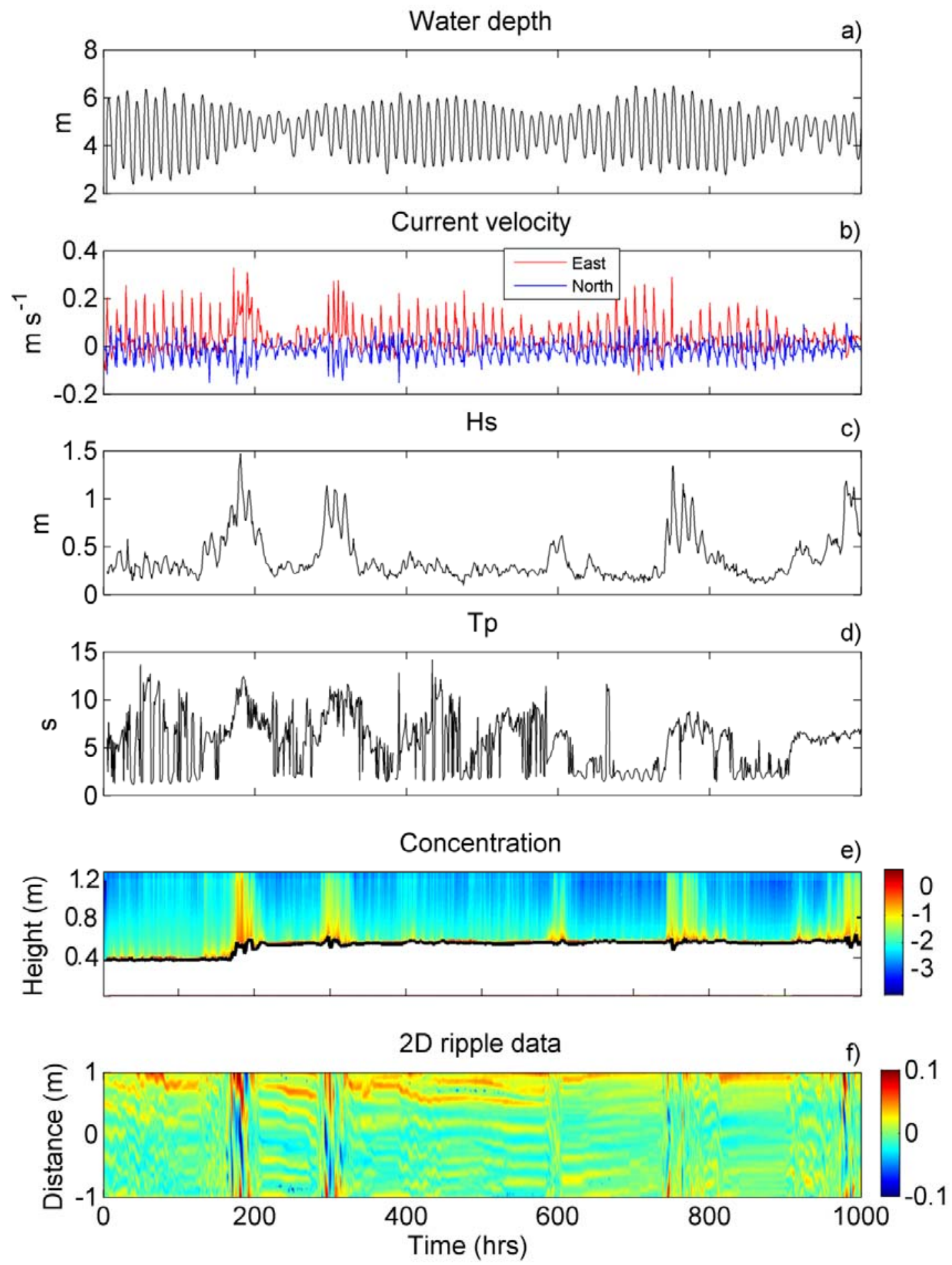

Fig. 2 


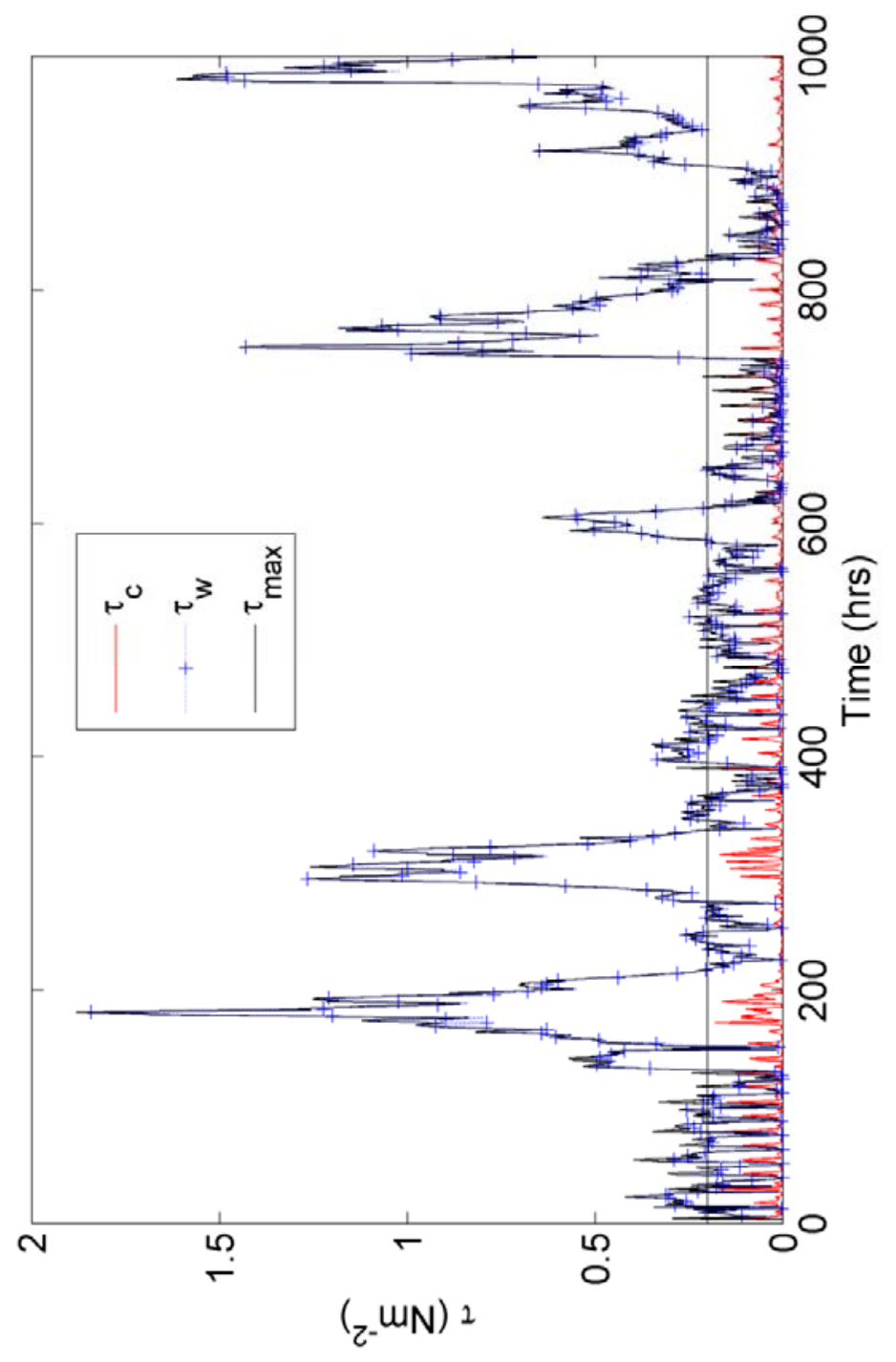

Fig. 3 


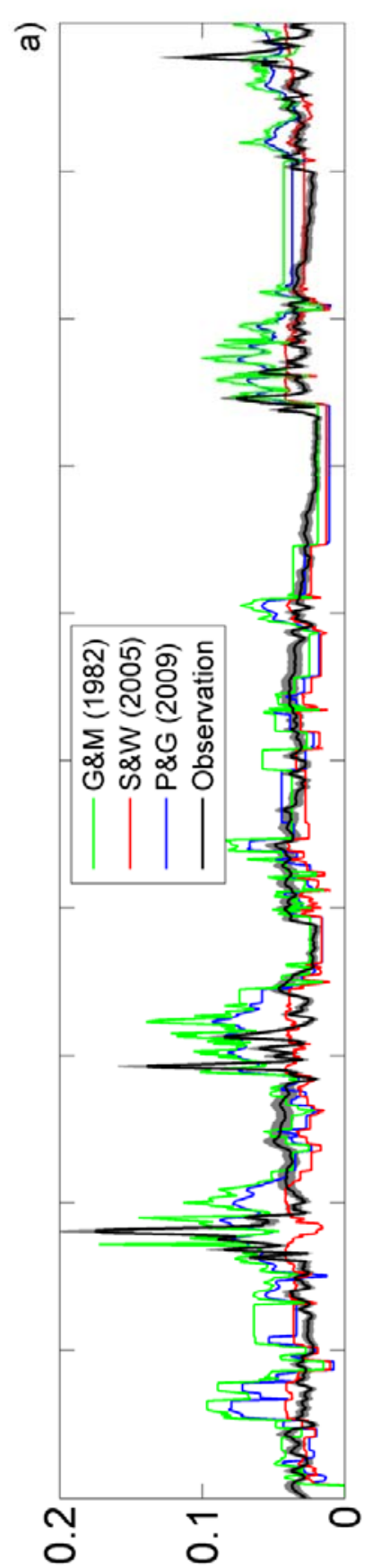

(w) $\mathrm{l}$

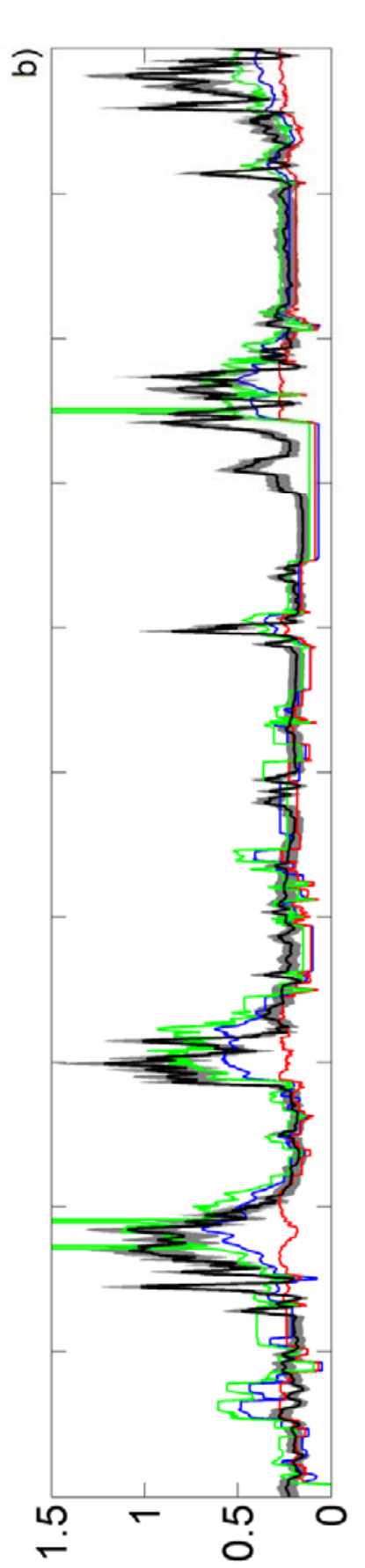

(u) $\chi$

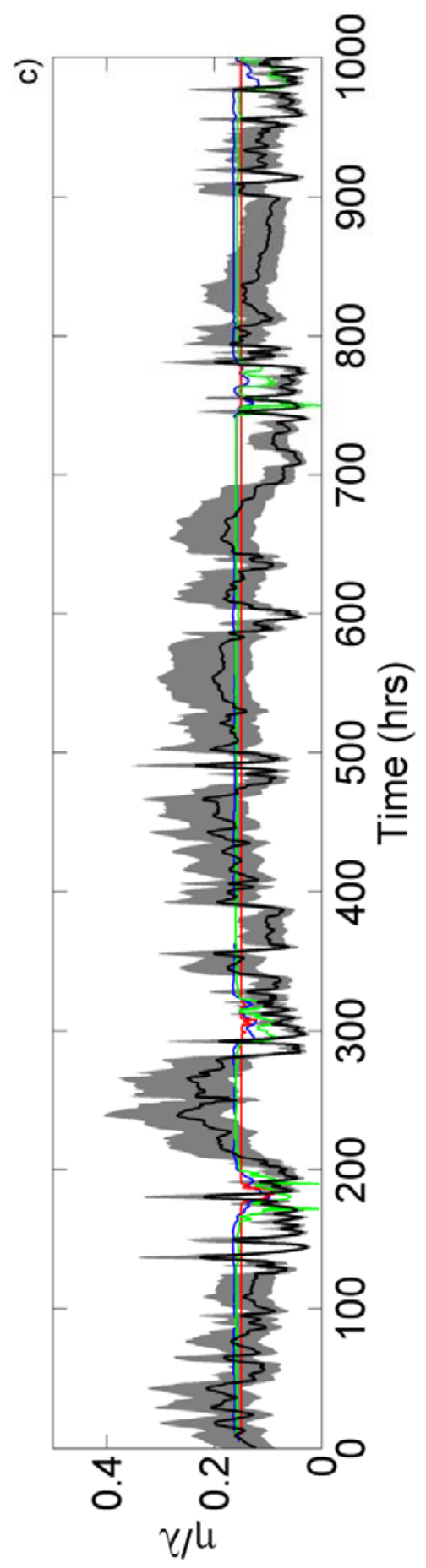

Fig. 4 

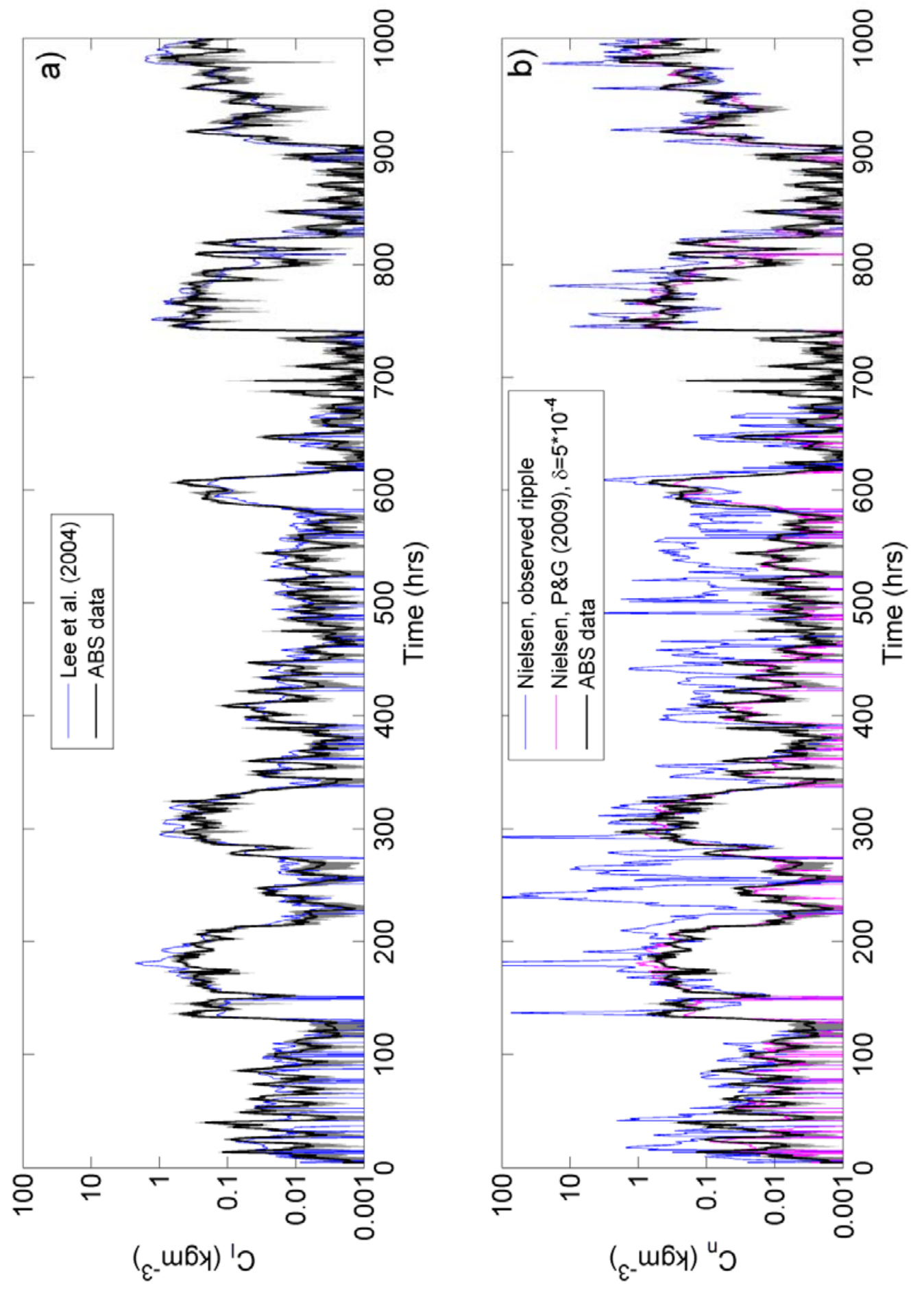

Fig 5 

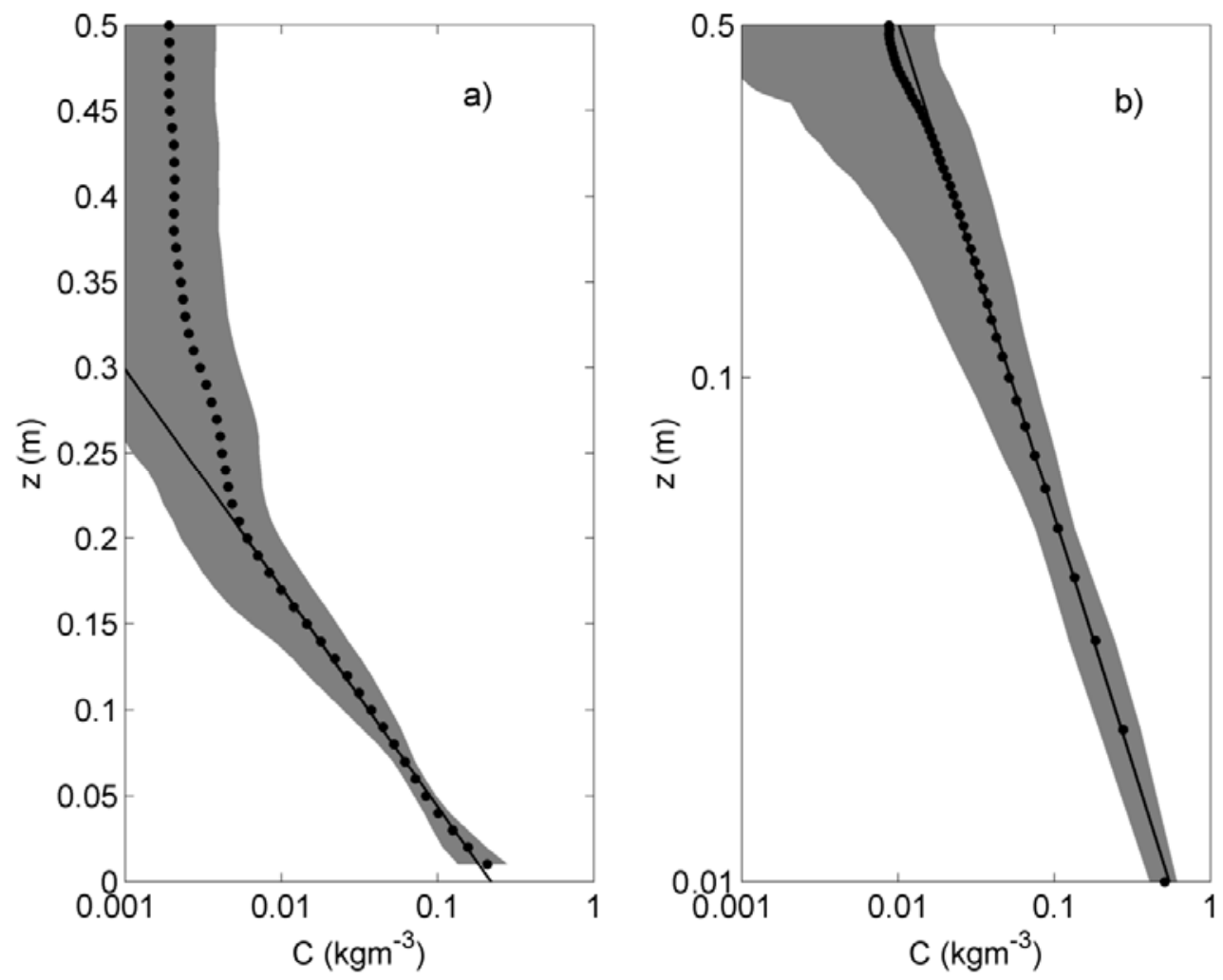

Fig 6 


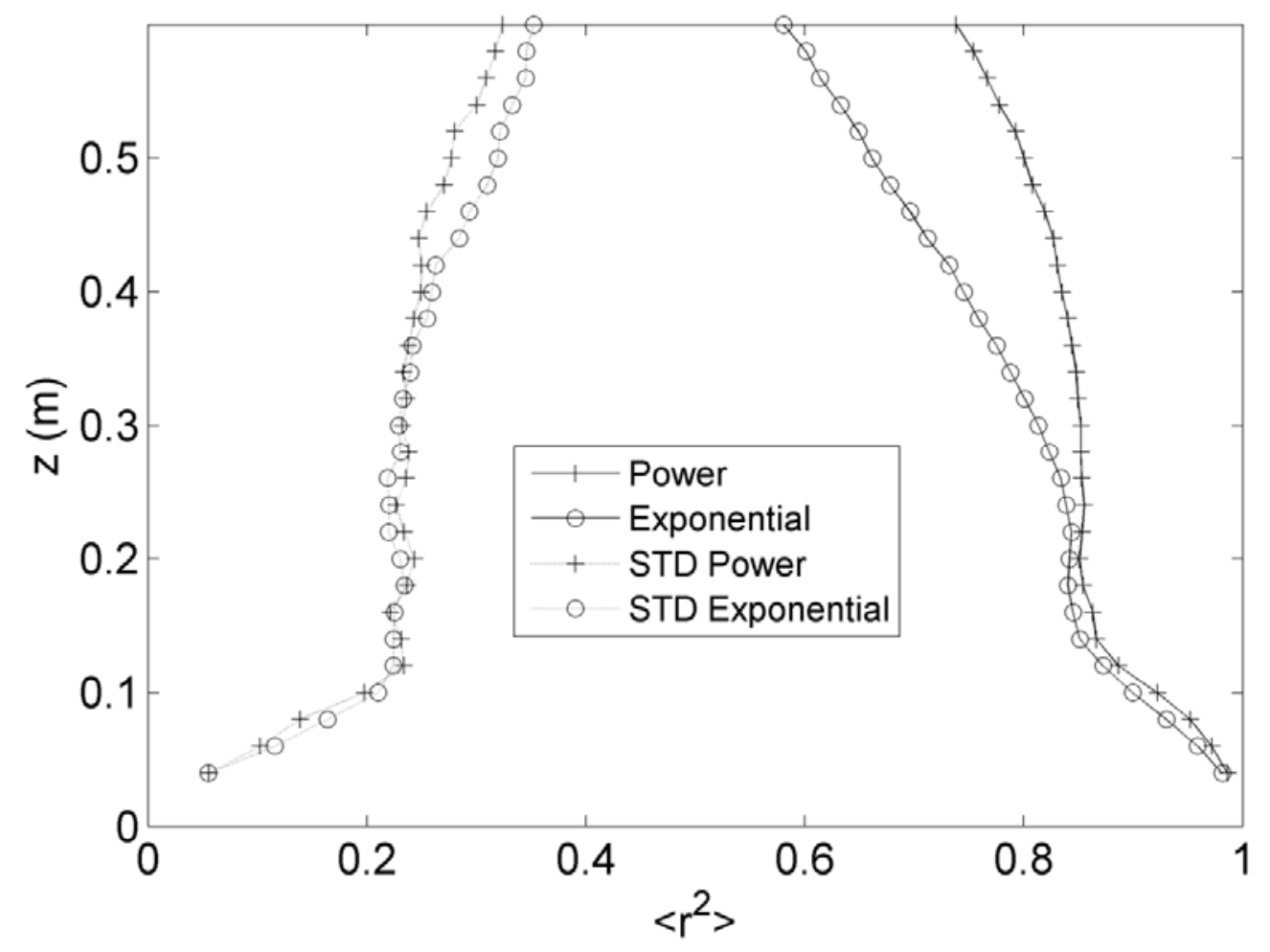

Fig 7 
a)
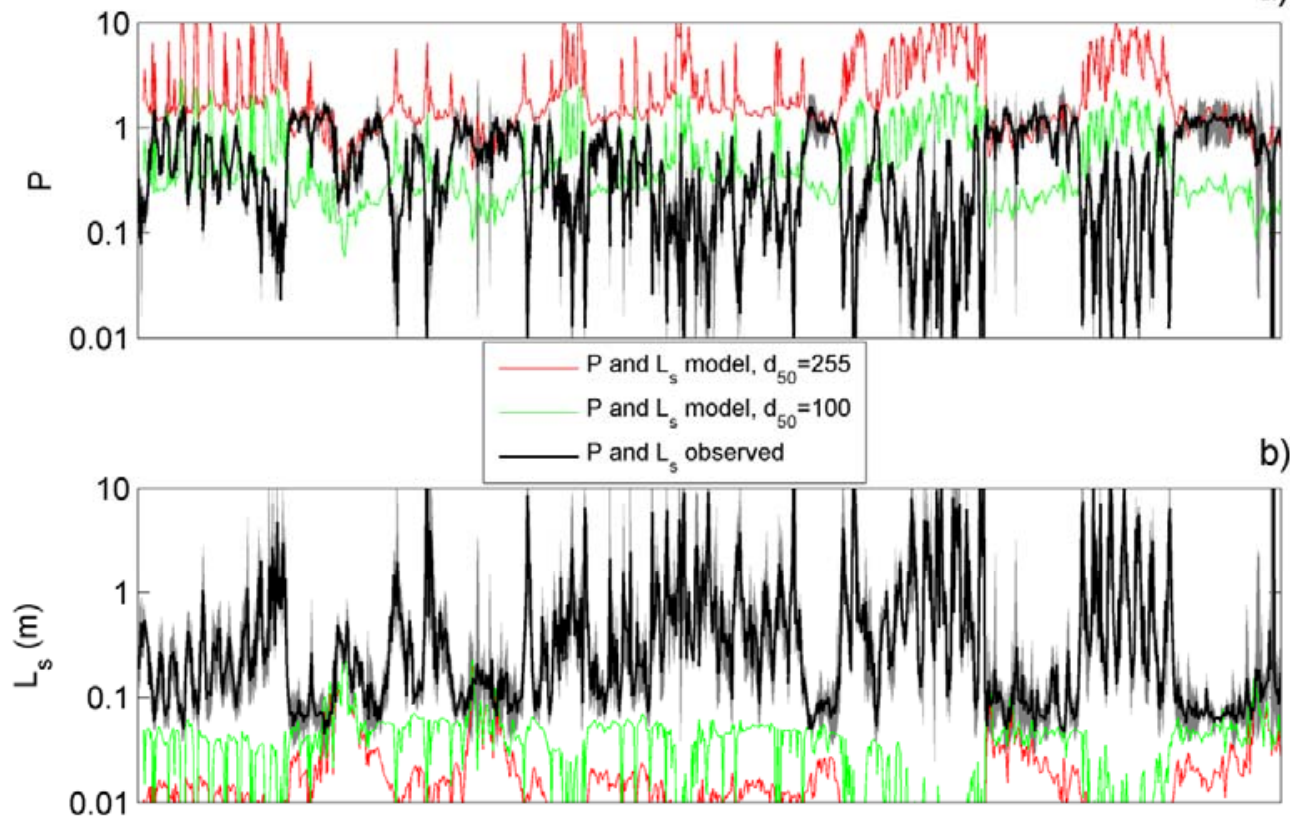

c)
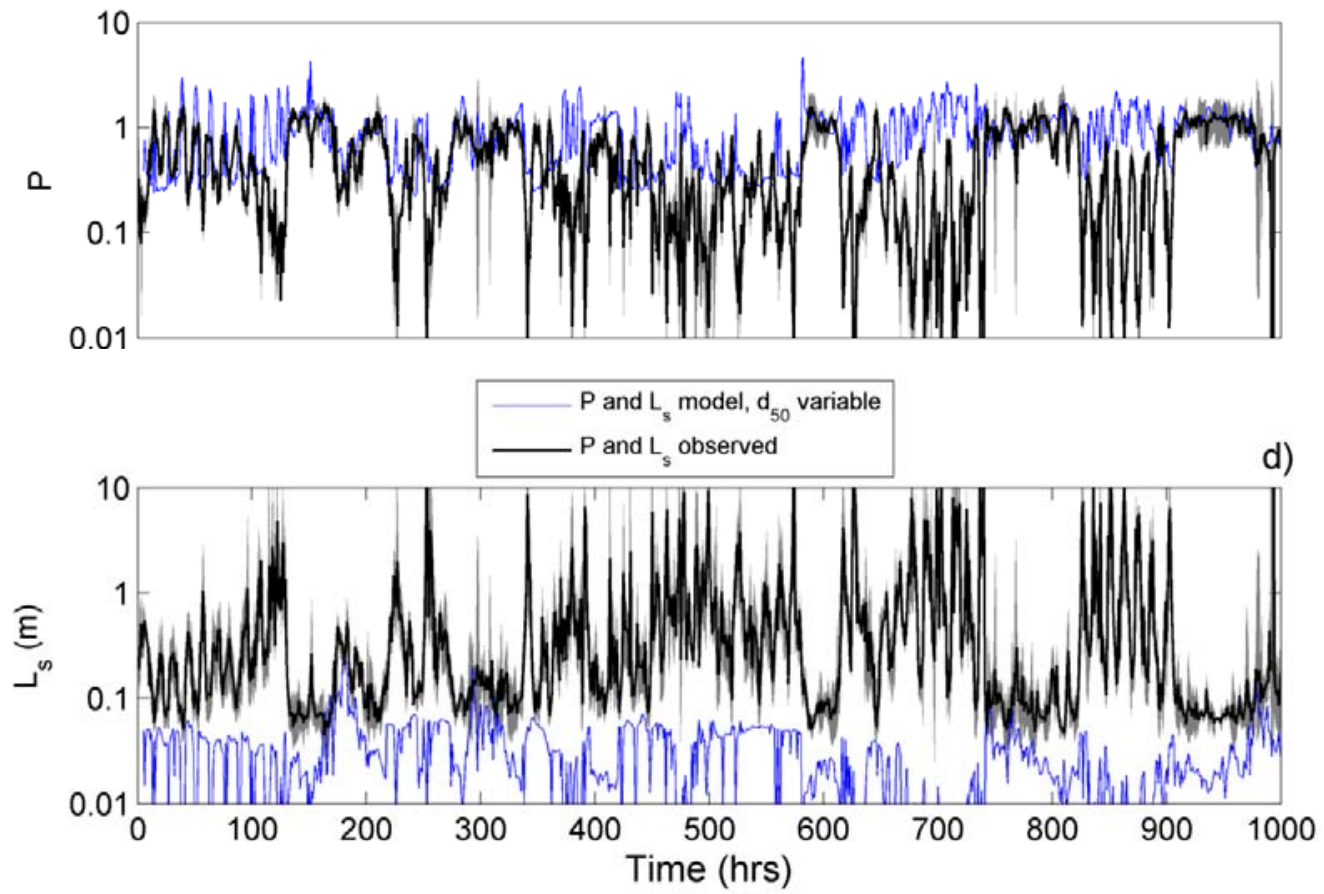

Fig 8 


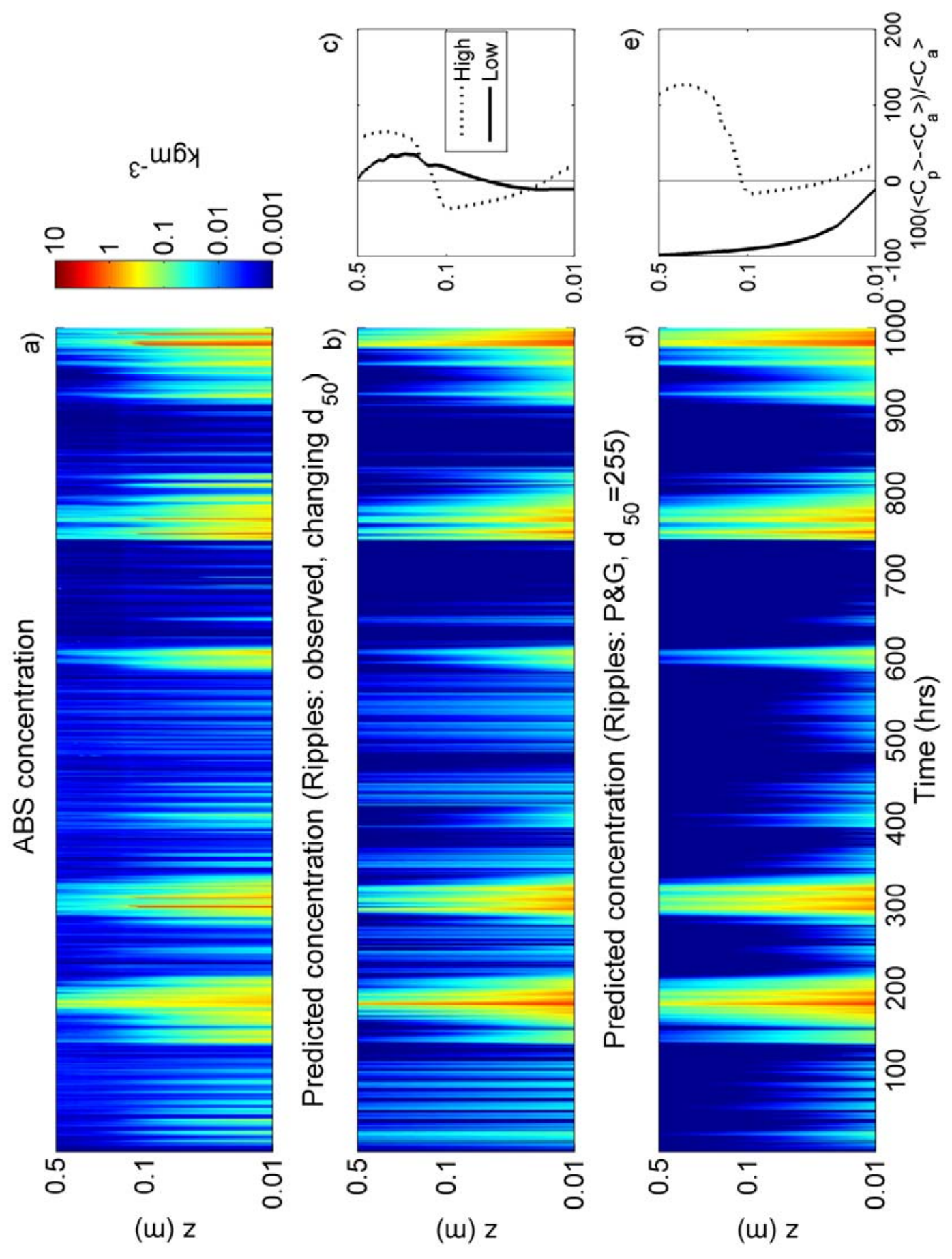

Fig 9 